\title{
Effect of Hydrostatic Pressure on LPSO Kinking and Microstructure Evolution of Mg-11Gd-4Y-2Zn-0.5Zr Alloy
}

\author{
Ce Zheng ${ }^{1,2} \cdot$ Shuai-Feng Chen ${ }^{1,3} \cdot$ Rui-Xue Wang $^{1} \cdot$ Shi-Hong Zhang ${ }^{1} \cdot$ Ming Cheng $^{1}$
}

Received: 18 February 2020 / Revised: 27 May 2020 / Accepted: 31 May 2020 / Published online: 14 August 2020

(c) The Chinese Society for Metals (CSM) and Springer-Verlag GmbH Germany, part of Springer Nature 2020

\begin{abstract}
Two different kinds of hot compressions, namely normal-compression and can-compression, were performed on the $\mathrm{Mg}-11 \mathrm{Gd}-4 \mathrm{Y}-2 \mathrm{Zn}-0.5 \mathrm{Zr}$ alloy, featured with long period stacking ordered (LPSO) phase. The kinking behavior of LPSO phase and microstructure evolution was investigated to clarify the effect of levels of imposed hydrostatic pressure. The results suggest that the LPSO phases including both the intragranular 14H-LPSO phase and intergranular 18R-LPSO phase suffer severe kinking behavior under higher hydrostatic pressure induced by can-compression, which is firstly characterized with more kinking times and smaller relative kinking width. The main reason for such enhanced LPSO kinking during cancompression may be mainly ascribed to the higher dislocation density under a higher level of hydrostatic pressure. Meanwhile, a competitive relationship between the kink behaviors of intergranular 18R-LPSO phase and intragranular 14H-LPSO phase was observed. That is, the intergranular 18R-LPSO phase only kinks obviously on the condition that the surrounded intragranular 14H-LPSO phase scarcely kinks. In contrast to the distinctive kinking of LPSO phase, the dynamic recrystallization (DRX) mechanism shows less dependence on the hydrostatic pressure. Resultantly, similar DRX fractions and crystallographic texture were attained for two compression processes owing to the similar operation of deformation mode.
\end{abstract}

Keywords Magnesium alloy $\cdot$ Hydrostatic pressure $\cdot$ Long period stacking ordered (LPSO) phase $\cdot$ Kinking $\cdot$ Dynamic recrystallization

\section{Introduction}

Wrought magnesium $(\mathrm{Mg})$ alloys, as the most promising lightweight alloys, are attracting considerable attentions due to the merits of low densities, high strength stiffness, and easy recycling [1-4]. In recent years, $\mathrm{Mg}$ alloys with addition of rare earth elements (e.g., Gd, Y, Ce) have been elaborately designated for improving their strength and ductility [5-12]. For instance, the addition of Gd can refine the

Available online at http://link.springer.com/journal/40195.

Ming Cheng

mcheng@imr.ac.cn

1 Institute of Metal Research, Chinese Academy of Sciences, Shenyang 110016, China

2 University of Chinese Academy of Sciences, Beijing 100049, China

3 Department of Materials Science and Engineering and Research Institute of Advanced Materials (RIAM), Seoul National University, Seoul 08826, Republic of Korea as-cast microstructure of $\mathrm{Mg}-\mathrm{Gd}-\mathrm{Al}-\mathrm{Zn}$ alloy as a result of presence of $\mathrm{Al}_{2} \mathrm{Gd}$ compound [8] and simultaneously induce notable solid solution strengthening due to atom size misfits and valency effects [9]. Besides, the ductility of Gd alloyed $\mathrm{Mg}$ alloys is increased by activating more non-basal slip systems [10]. In addition, similar role of $\mathrm{Y}$ addition was found [11], and the mixture addition of $\mathrm{Y}$ and Ce obviously enhanced the mechanical strength with a slight decrease in plasticity by strengthening of solution, dispersion, and grain refinement [12]. Among these RE-contained alloys, Mg-TM (transition metals, $\mathrm{Zn}, \mathrm{Cu}$, etc.)- $\mathrm{RE}$ alloys featured with metallurgical induced long period stacking ordered (LPSO) phase have been the most investigated alloys. As a second phase with high hardness, high elastic modulus, strong anisotropy, and coherent interfaces with Mg matrix, the LPSO phase has been proved to efficiently hinder the dislocations motion and strengthen the Mg-RE alloy via an analogous fiber-reinforced mechanism after extrusion, especially in ascast and solution states with coarse grains and very limited nano-sized precipitates [13-15]. 
During plastic deformation, kinking of the LPSO phase occurs, as a result of profuse activation of basal $\langle a\rangle$ dislocations, and it is considered to be the main deformation mechanism for LPSO phase [13]. Actually, it indicates that the activation of deformation mode strongly depends on the crystallographic texture and loading direction, which in turn affects the kinking behavior of LPSO phase [14]. When the loading is favorable for basal $\langle\boldsymbol{a}\rangle$ slip activation, it facilitates the kinking of LPSO phase, and a higher dislocation density was developed due to the kinking [15]. In contrast, non-basal slips could be activated instead to accommodate the strain inside LPSO phase under an inverse loading sense [16]. Therefore, distinctive deformation behavior can be launched for LPSO phase according to the difference in the loading direction and stress states.

Generally, thermal-mechanical processes, including hot extrusion [17-19], rolling [20], upsetting [21], and forging [22], are always utilized for RE-contained $\mathrm{Mg}$ alloys to refine the microstructure and tailor the crystallographic texture, which can further improve their mechanical properties and formability. During these processes, complex loading conditions and stress states are inevitably involved, and simultaneously, different levels of hydrostatic pressure are induced. Moreover, it has been experimentally demonstrated that a much severe kinking of LPSO phase was observed for hot extrusion than for hot rolling under the similar strain level [20].

Although numerous studies have been done to clarify the influence of hydrostatic pressure, these efforts just focus on correlating the elastic module, yielding stress, and flow stress with the imposed level of hydrostatic pressure at room temperature [23-26]. In addition, the hydrostatic pressure contributes to the Peierls-Nabarro stress of the dislocation movement and the enthalpy of vacancy migration, which governs the annihilation of dislocations via edge climbing, resulting in the increase in dislocation density [27]. However, till now, it is still unclear about the reason why severe LPSO kinking can be expected for hot forming conditions such as extrusion and forging.

In the present study, hot normal-compression and can-compression were conducted on a casting Mg-11Gd-4Y-2Zn-0.5Zr (wt\%), namely GWZK 114 alloy, at different hydrostatic pressure levels with the temperature range of $300-450{ }^{\circ} \mathrm{C}$. The microstructure and texture evolution of GWZK 114 alloy was investigated. Specially, the kinking behaviors of LPSO phase under two compression conditions were quantitatively characterized to clarify the effect of hydrostatic pressure.

\section{Experimental}

The as-cast GWZK 114 alloy with an actual compositions of $10.8 \% \mathrm{Gd}, 3.93 \% \mathrm{Y}, 1.94 \% \mathrm{Zn}, 0.37 \% \mathrm{Zr}$, and balance $\mathrm{Mg}$ (in mass fraction) was prepared by semi-continuous casting method as a cylindrical ingot of $\Phi 330 \mathrm{~mm} \times 650 \mathrm{~mm}$. High-purity $\mathrm{Mg}$ (99.95\%), Zn (99.95\%), Mg-25Gd (wt\%), $\mathrm{Mg}-25 \mathrm{Y}$ (wt\%), and Mg-30Zr (wt\%) master alloys were melted in an electrical resistance furnace at temperature of $730{ }^{\circ} \mathrm{C}$ under a mixed gas of $\mathrm{CO}_{2}$ and $\mathrm{SF}_{6}$ with a volume ratio of 99:1. Then, a preheated steel mold with temperature of $200{ }^{\circ} \mathrm{C}$ was utilized for the casting process. The microstructure of as-cast GWZK 114 alloy has been systematically characterized and presented in our recent study [28], which was not shown here for the purpose of simplicity.

The as-cast material was homogenized at $500{ }^{\circ} \mathrm{C}$ for $16 \mathrm{~h}$ in a resistance furnace and then cooled in air. Here, normalcompression and can-compression were employed to introduce different levels of hydrostatic pressure. For the normalcompression, standard cylinder samples with a diameter of $8 \mathrm{~mm}$ and a height of $12 \mathrm{~mm}$ were prepared. For the cancompression (Fig. 1b), the samples consisted of two parts: inner GWZK 114 alloy cylinder (a height of $10 \mathrm{~mm}$ and a diameter of $3 \mathrm{~mm}$ ) and outer Inconel 718 (IN718) superalloy can (the same height of $10 \mathrm{~mm}$, and its inner and outer diameters being $3 \mathrm{~mm}$ and $7 \mathrm{~mm}$, respectively). The IN718 superalloy was chosen as can material for its good thermal stability below the temperature of $500{ }^{\circ} \mathrm{C}[29]$.

These two kinds of samples were compressed to a nominally true strain of 0.8 at $300{ }^{\circ} \mathrm{C}, 350{ }^{\circ} \mathrm{C}, 400{ }^{\circ} \mathrm{C}$, and $450{ }^{\circ} \mathrm{C}$ with a constant strain rate of $0.01 \mathrm{~s}^{-1}$ by using Gleeble- 3800 thermo-mechanical simulator under a low vacuum $\left(<10^{-3}\right.$ $\mathrm{Pa}$ ). To minimize the friction force between compression anvil and the samples, graphite powder was used as lubrication. During compression, the samples were heated to designated temperature at a constant rate of $5{ }^{\circ} \mathrm{C} / \mathrm{s}$, and after compression, the samples were quickly water quenched to maintain the deformed microstructure. Additionally, the thermo-mechanical finite element method (FEM) simulations were carried out by using Abaqus/Explicit 6.13 to evaluate the levels of imposed strain and hydrostatic pressure. It is noteworthy that the mechanical behaviors of casting GWZK 114 and IN718 alloys used for FEM simulations are not shown here for simplicity, and particularly, the flow stress for IN718 alloy was individually measured at various temperatures. The simulated results were compared with the experiment at $300{ }^{\circ} \mathrm{C}$, as shown in Fig. 1a, b. Furthermore, the evolution of effective plastic strain and stress triaxiality of the selected elements at center of samples is displayed in Fig. 1c, d, respectively. As can be seen, almost same strains $(\varepsilon=2.5)$ were obtained for normal-compression and can-compression with only a maximum deviation less than 0.2 at $300{ }^{\circ} \mathrm{C}$, while the final stress triaxiality of normal type is only -1.33 , which is obviously lower than that of can type. The stress triaxiality is a commonly used parameter to evaluate the stress state, which is defined as the ratio between hydraulic pressure $\left(\sigma_{\mathrm{kk}}\right)$ and equivalent stress $\left(\bar{\sigma}_{\mathrm{m}}\right)$, i.e., $\sigma_{\mathrm{tri}}=\sigma_{\mathrm{kk}} / \bar{\sigma}_{\mathrm{m}}[30]$. The higher negative $\sigma_{\text {tri }}$ 


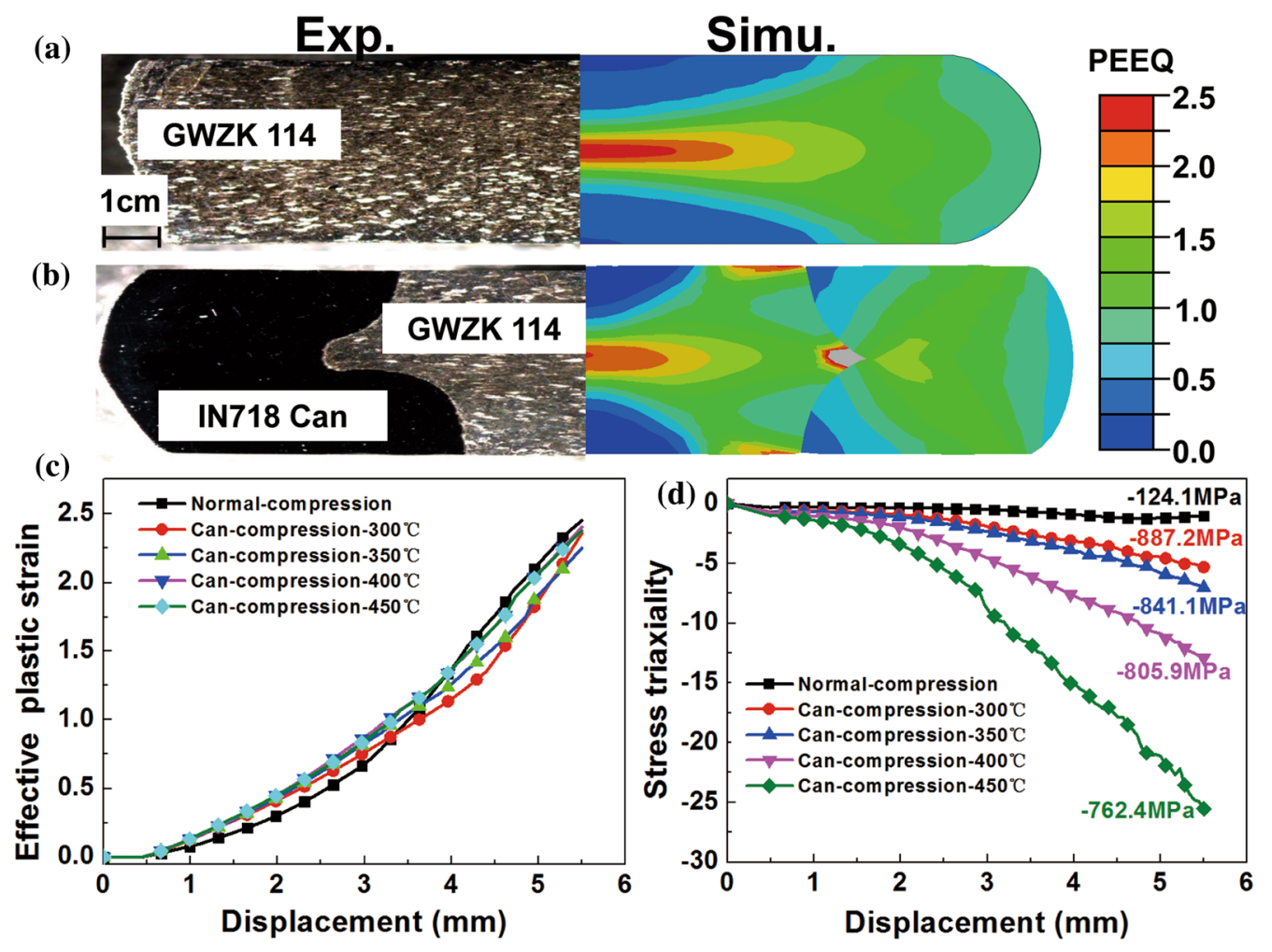

Fig. 1 Distribution of effective plastic strain for a normal-compression, $\mathbf{b}$ can-compression at final state; evolution of $\mathbf{c}$ effective plastic strain, $\mathbf{d}$ stress triaxiality for the selected center element

values in can-compression indicate that larger hydrostatic pressures ranging from 762.4 to $887.2 \mathrm{MPa}$ are successfully introduced, and they are much higher than $124.1 \mathrm{MPa}$ in normal-compression.

In order to examine the microstructure and texture of as-homogenized and as-deformed samples, characterizing methods including optical microscopy (OM), scanning electron microscope (SEM), and electron backscatter diffraction (EBSD) were employed. And all the observation regions were selected at the center of deformed samples. The OM and SEM specimens were prepared by mechanical polishing and then etched for 6-10 $\mathrm{s}$ in a solution $(1 \mathrm{~g}$ picric acid, $2 \mathrm{~mL}$ acetic acid, $2 \mathrm{~mL}$ pure water, and $14 \mathrm{~mL}$ alcohol). The EBSD specimens were further electrolytic polished for $120-150 \mathrm{~s}$ by a solution $10 \%$ perchlorate and $90 \%$ alcohol at temperature of -30 to $-35{ }^{\circ} \mathrm{C}$. The scanning step size of EBSD was set as $0.8 \mu \mathrm{m}$, and all the EBSD data were analyzed with the HKL Channel 5 software. The critical angle of $15^{\circ}$ was chosen to distinguish low-angle grain boundary (LAGB, $2^{\circ}-15^{\circ}$, marked with white lines) from high-angle grain boundary (HAGB, $15^{\circ}-100^{\circ}$, marked with black lines). Meanwhile, a cutoff angle of $2^{\circ}$ was set as the minimum boundary misorientation. In addition, the transmission electron microscope (TEM) was also conducted for LPSO structure characterization. The specimens were mechanically polished to $30-50 \mu \mathrm{m}$ and then ion thinning via a Leica 101 operated with scanning angle of $8^{\circ}-15^{\circ}$, and accelerating voltage of $5 \mathrm{kV}$ and then at FEI Tecnai G2 F20 with accelerating voltage being $200 \mathrm{kV}$.

\section{Results}

\subsection{Initial Microstructure of GWZK 114 Alloy}

Figure 2 shows the as-homogenized microstructure of GWZK114 alloy. From Fig. 2a, the microstructure of as-homogenized alloy consists of equiaxed grains with an average size of $73 \mu \mathrm{m}$ as shown in Fig. $2 \mathrm{~b}$ and intergranular phase with an area fraction of $\sim 15 \%$. Meanwhile, the (0001) pole figure (PF) in Fig. 2c reveals nearly random grain orientations with a maximum texture intensity of 5.74 m.u.d. (multiple of uniform distribution). On the backscattered electron (BSE) image in Fig. 2d, three kinds of phases are indentified based on the color contrast, as marked by points A, B, and C. After analyzed by energy dispersion spectrum (EDS) as shown in Fig. $2 \mathrm{~g}-\mathrm{i}$, the compositions of points $\mathrm{A}, \mathrm{B}, \mathrm{C}$ are determined to be $\mathrm{Mg}_{88.68} \mathrm{Gd}_{3.66} \mathrm{Y}_{3.12} \mathrm{Zn}_{4.54}, \mathrm{Mg}_{75.28} \mathrm{Gd}_{14.04} \mathrm{Y}_{4.83} \mathrm{Zn}_{5.80} \mathrm{Zr}_{0.05}$, $\mathrm{Mg}_{96.42} \mathrm{Gd}_{1.76} \mathrm{Y}_{1.31} \mathrm{Zn}_{0.45} \mathrm{Zr}_{0.06}$, respectively, which are 

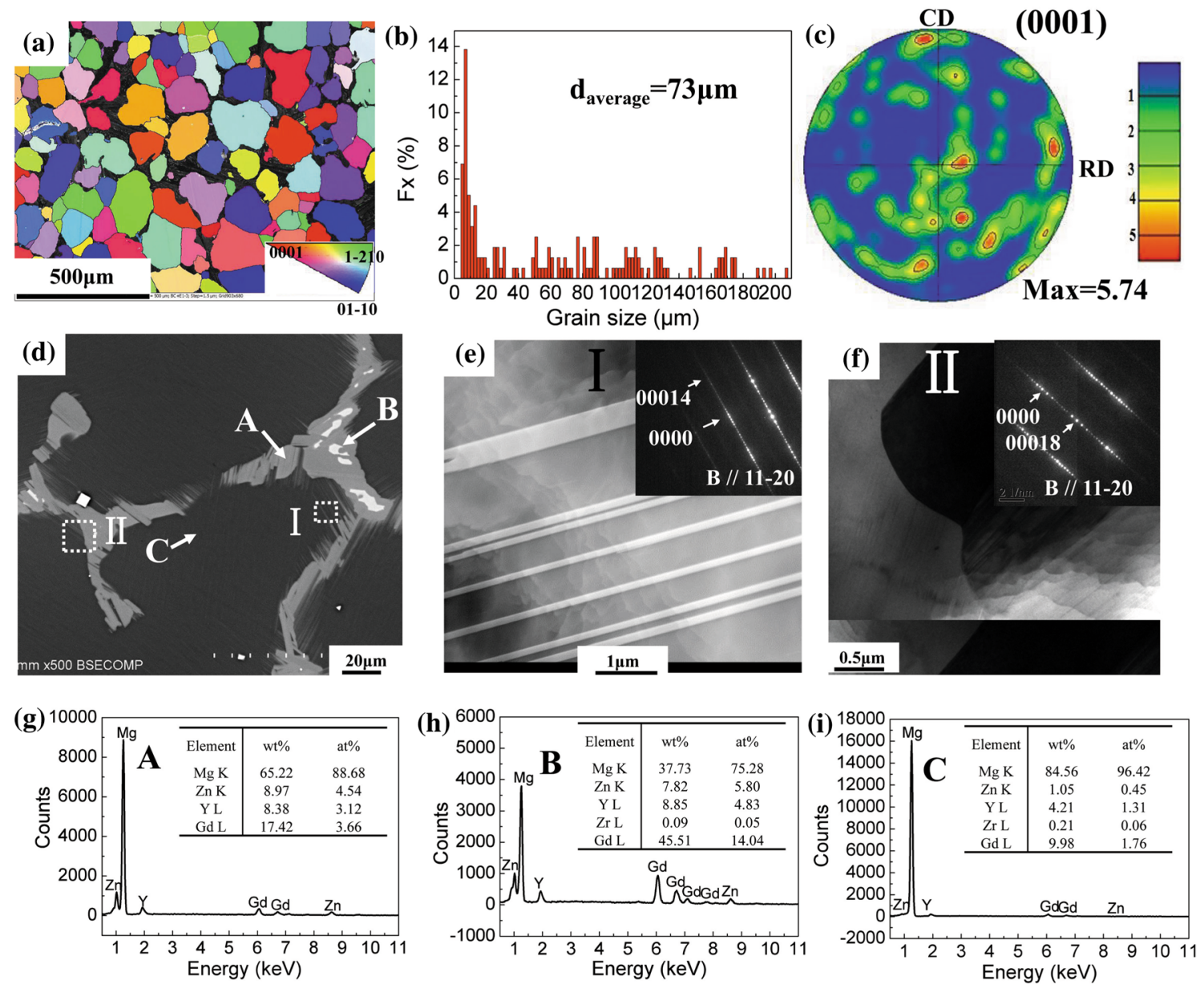

Fig. 2 EBSD results of as-homogenized GWZK114 alloy a orientation imaging microscopy (OIM); b statistical distribution of grain size; c (0001) pole figure (PF); $\mathbf{d}$ backscattered electron (BSE) image; TEM results of $\mathbf{e}$ intragranular needle-like phase; $\mathbf{f}$ intergranular bulk phase; $\mathbf{g}-\mathbf{i}$ EDS results of points $\mathrm{A}, \mathrm{B}$, and $\mathrm{C}$ in Fig. 2d. The $\mathrm{CD}$ and $\mathrm{RD}$ indicate the compression and radial directions, respectively
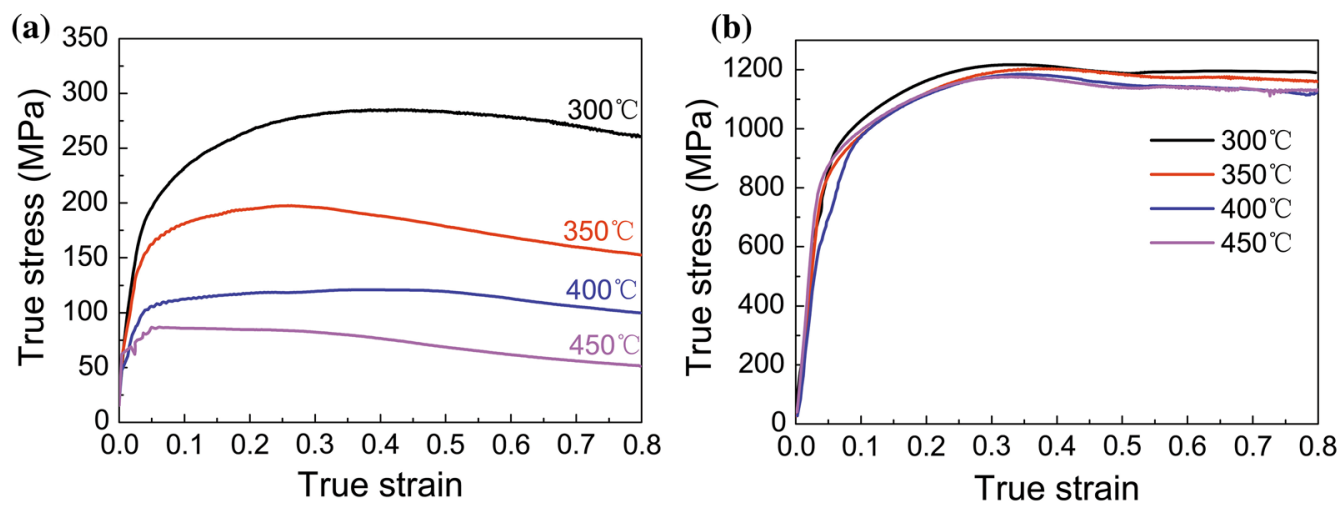

Fig. 3 True stress-true strain curves of a normal-compression, $\mathbf{b}$ can-compression under different temperatures

corresponding to be intergranular LPSO phase, eutectic phase, and $\alpha-\mathrm{Mg}$ matrix. The corresponding bright field TEM figures and selected area diffraction (SAD) results of needle-like phase (area I in Fig. 2d) and bulk phase (area II in Fig. 2d) are shown in Fig. 2e, f, respectively. It can be confirmed that the needle-like phase is $14 \mathrm{H}$-LPSO phase 


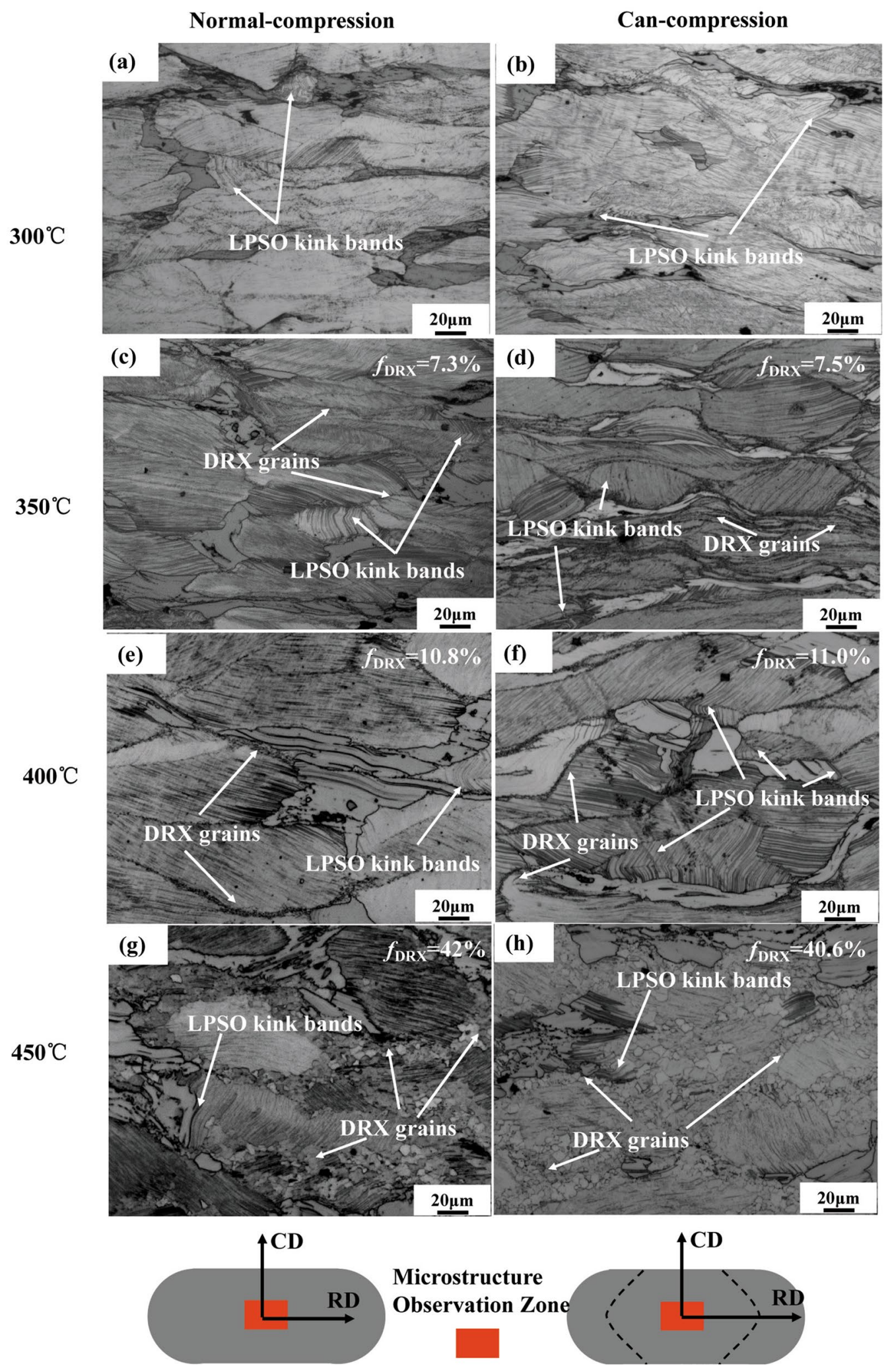

Fig. 4 OM microstructure of as-compressed GWZK 114 alloy under two hydrostatic pressures for different deformation conditions. The DRX area fractions are also presented and calculated as $f_{\mathrm{DRX}}=S_{\mathrm{DRX}} /\left(S_{\mathrm{All}}-S_{\text {Inter }}\right)$ with $S_{\mathrm{DRX}}$ and $S_{\text {Inter }}$ being the areas of DRX grains and intergranular phases, respectively 

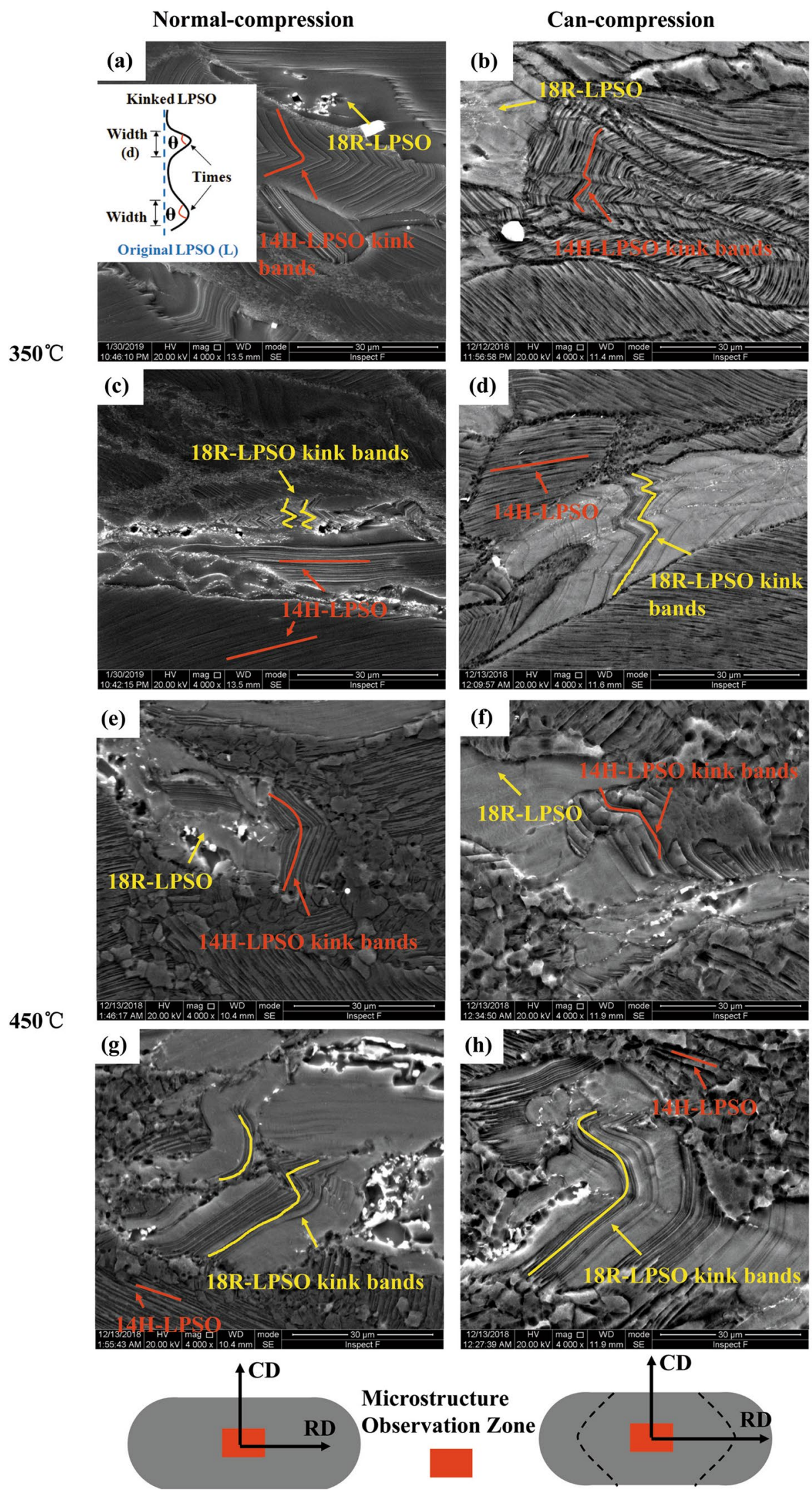
4 Fig. 5 SEM images of the kink behavior of LPSO phases under different conditions; $14 \mathrm{H}$ and 18R-LPSO phases were marked by red and yellow lines, respectively, and the curved ones represent the kinking of LPSO phase

for the additional thirteen spots appearing (0002) diffraction [31], and the bulk phase is 18R-LPSO phase as the weaker spots at positions $n / 6$ of the (0002) diffraction [13].

\subsection{Flow Stress Curves of GWZK 114 Alloy Under Compression Conditions}

Figure 3 presents the true stress-strain curves of GWZK 114 alloy under normal-compression and can-compression conditions at temperature of $300-450{ }^{\circ} \mathrm{C}$ with strain rate of $0.01 \mathrm{~s}^{-1}$. The yield stresses of GWZK 114 alloy under normal-compression decreased with the temperature from about $200 \mathrm{MPa}$ at $300{ }^{\circ} \mathrm{C}$ to $75 \mathrm{MPa}$ at $450{ }^{\circ} \mathrm{C}$ as shown in Fig. 3a. After the peak stress, the flow stresses decreased with the strain at the temperature of $350-450{ }^{\circ} \mathrm{C}$, which means that the DRX happened. As for the flow stress-strain curves of GWZK 114 alloy under can-compression, the flow stresses were the mixture of IN 718 superalloy and GWZK 114 alloy, resulting in the stably higher yield stress (about $900 \mathrm{MPa}$ ). In consistence with Ref. [29], it indicates that the IN718 superalloy has a good thermal stability below the temperature of $500{ }^{\circ} \mathrm{C}$.

\subsection{Microstructure Characteristics of As-Compressed GWZK 114 Alloy}

Figure 4 presents the OM microstructure of GWZK 114 alloy compressed to a strain of 0.8 by normal and can methods at different temperatures, which were selected at the center part of deformed samples, as illustrated by the red squares in Fig. 4. After normally deformed at $300{ }^{\circ} \mathrm{C}$ (Fig. 4a) and $350^{\circ} \mathrm{C}$ (Fig. 4c), the grains are obviously elongated along RD, and simultaneously, kinking bands of LPSO phases are widely observed. As the temperature increases to $400{ }^{\circ} \mathrm{C}$ (Fig. 4e), the matrix grains are less compressed with formation of lots of fine new grains at the vicinity of grain boundaries (GBs). This indicates that the dynamic recrystallization (DRX) has been noticeably triggered at this temperature. Compared with $300{ }^{\circ} \mathrm{C}$ and $350{ }^{\circ} \mathrm{C}$, a weaker LPSO kinking behavior is detected at $400{ }^{\circ} \mathrm{C}$. At $450{ }^{\circ} \mathrm{C}$ (Fig. $4 \mathrm{~g}$ ), the originally coarse and equiaxed grains are flattened into an elliptical shape, and amounts of new finer grains are observed near the grain boundaries, which result in a "necklace" structure. Correspondingly, the LPSO phases only marginally kink with small angles.

Figure $4 \mathrm{~b}, \mathrm{~d}, \mathrm{f}, \mathrm{h}$ shows the microstructure of GWZK 114 alloy under can-compression conditions. After can-compressed at $300{ }^{\circ} \mathrm{C}$, similarly elongated grains were detected in a kind of "streamline" morphology. For the LPSO phases, severe kinking behavior featured by multiple bands was found (as indicated by white arrows in Fig. 4b). With the temperature ranging from $350{ }^{\circ} \mathrm{C}$ to $400{ }^{\circ} \mathrm{C}$ (Fig. $4 \mathrm{f}$ ), some DRX grains were formed along grain boundaries. When can-compressed at $450{ }^{\circ} \mathrm{C}$ (Fig. 4h), more DRX grains were observed at the grain boundaries and even within grains. Moreover, similar evolution tendency of LPSO kinking behaviors was observed, that is, the kinking of LPSO phases became gradually modest with the temperature rising, whereas it still can be sure that the LPSO kinking under can-compression is more considerable, which will be detailed presented in following section. In addition, the DRX fractions are almost identical for normal-compression and can-compression with different deformation conditions, and the maximum derivation is just $1.4 \%$ at $450{ }^{\circ} \mathrm{C}$.

\subsection{LPSO Kink Behavior Under Two Hydrostatic Pressure Compressions}

As observed in Fig. 4, although similar evolution of microstructure was detected between normal-compression and can-compression, the deformable LPSO phases undergo severe kinking behavior under the can loading. To clarify such differences in kinking behavior more specially, kink bands of LPSO phases including both 14H and 18R types are further investigated via SEM magnification observations, as shown in Fig. 5. In this figure, only the microstructure of $350{ }^{\circ} \mathrm{C}$ and $450{ }^{\circ} \mathrm{C}$ is presented for the purpose of simplicity.

At $350{ }^{\circ} \mathrm{C}$, massive and dense kink bands of $14 \mathrm{H}$-LPSO phase can be observed inside the matrix of both normaland can-compressed samples, as shown in Fig. 5a, b. In can-compression, kink bands with zigzag morphology are formed indicating larger times of kinking. At a higher temperature of $450{ }^{\circ} \mathrm{C}$ (Fig. 5e, f), the kinking times of $14 \mathrm{H}-\mathrm{LPSO}$ phase decrease in both loading cases, while the kinking width increases, whereas compared with the normal-compression, larger times and smaller width of LPSO kinking are still observed for the can-compression. As to the intergranular 18R-LPSO phase (Fig. 5c, d, g, h), similar evolution tendency of kink band is detected. That is, the kinking times of 18R-LPSO kink bands are also larger during can-compression. Additionally, a competitive kinking behavior exists between 14H-LPSO phase and 18R-LPSO phase irrespective with compression types and deformation conditions. From Fig. 5a, b, severe kinked 14H-LPSO phase occurs with the surrounding 18R-LPSO phase being almost free from kinking and vice versa in Fig. $5 \mathrm{c}$, d. The same phenomenon is also evidenced at the temperature of $450{ }^{\circ} \mathrm{C}$.

Figure 6 quantitatively compares the kink angle $\left(180^{\circ}-\theta\right)$, times, and relative width ratio (denoted as $d / L$ in Fig. 6) of both $14 \mathrm{H}$ and 18R-LPSO kink bands under normal-compression and can-compression. From Fig. 6a, higher kinking 

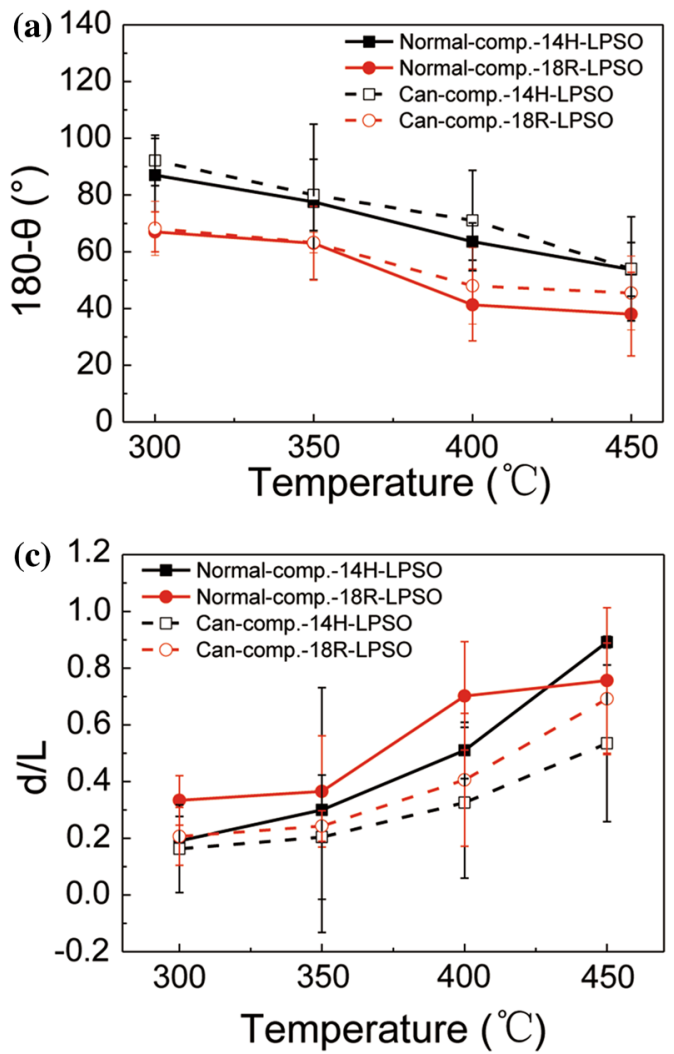

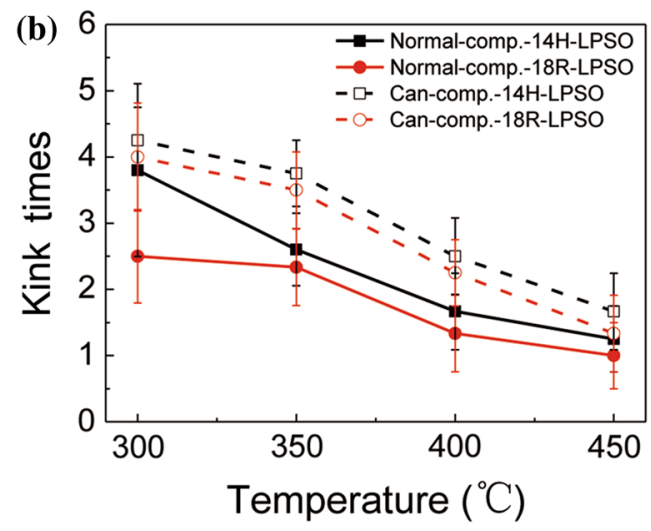

(d)

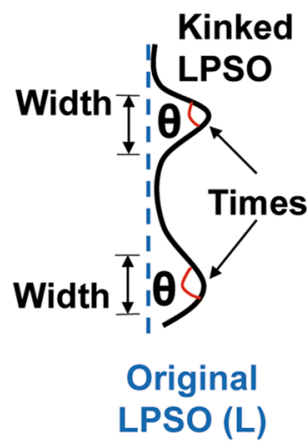

Fig. 6 Kinking behavior of LPSO phases in normal and can-compressed samples: a kink angle; $\mathbf{b}$ kink times; $\mathbf{c}$ relative width ratio of kink band $(d / L)$. d schematic of width, kink times and angle for kink band. For a certain deformation case in Fig. 6a-c, at least ten measures are taken for these statistics

angles are resulted for 14H-LPSO phase than for 18R-LPSO phase, in which the kink angles for can-compression are slightly higher. As shown in Fig. $6 \mathrm{~b}$ and c, the LPSO phases during can-compression display a larger kinking times and smaller relative width ratio at the same deformation conditions. Consistent with OM and SEM observation (Figs. 4, 5), the kink angles and times gradually decrease with a nearly linear trend with the temperatures increasing. Under the constraint of decreasing kink angle and times, a larger $d / L$ value is resulted.

\subsection{EBSD Analysis Under Two Hydrostatic Pressure Compressions}

Figure 7 shows EBSD results of GWZK 114 alloy after compressed at $350{ }^{\circ} \mathrm{C}$ and $450{ }^{\circ} \mathrm{C}$, where the black regions are non-indexed eutectic and LPSO phases [32]. In accordance with the OM results (Fig. 4c, d), the matrix grains are obviously elongated after compressed at $350{ }^{\circ} \mathrm{C}$, as given in Fig. 7a, b. Besides, amounts of LAGBs (white lines) could be found inside the matrix. Again, similarly low DRX fractions $(\sim 3 \%)$ are obtained, which are lower than these extracted from OM images because some fine DRX grains fail to be indexed during EBSD measurement. During compression, the initial random oriented grains (different colors in Fig. 2a) evolve to be monotonic orientations (mainly in red color), especially for the can-compression conditions. At $450{ }^{\circ} \mathrm{C}$ (Fig. 7c, d), a typically bimodal structure composed of deformed grains and DRX grains is detected, and LAGBs are still seen inside the deformed grains. The DRX fractions of normal-compression and can-compression gradually increased to $42.6 \%$ and $42.4 \%$, respectively. As well, similar average sizes of DRX grains are resulted being $3.24 \mu \mathrm{m}$ and $3.33 \mu \mathrm{m}$. In this study, the deformed grains are separated from the DRX grains through the differences in their grain sizes and grain orientation spread (GOS), i.e., grains with size and GOS smaller than $5 \mu \mathrm{m}$ and $2^{\circ}$ are identified as DRX grains [32]. Thus, different with the distinctive kinking behavior of LPSO phases displayed between normalcompression and can-compression, the DRX fractions and grain sizes are almost irrespective with loading methods.

Figure 8 shows the kernel average misorientation (KAM) maps, which can reflect the accumulation of deformation energy related to the dislocation density [33]. Consistent with the distribution of LAGBs (Fig. 7), at $350{ }^{\circ} \mathrm{C}$ almost all the grains are full of high values of local misorientation 

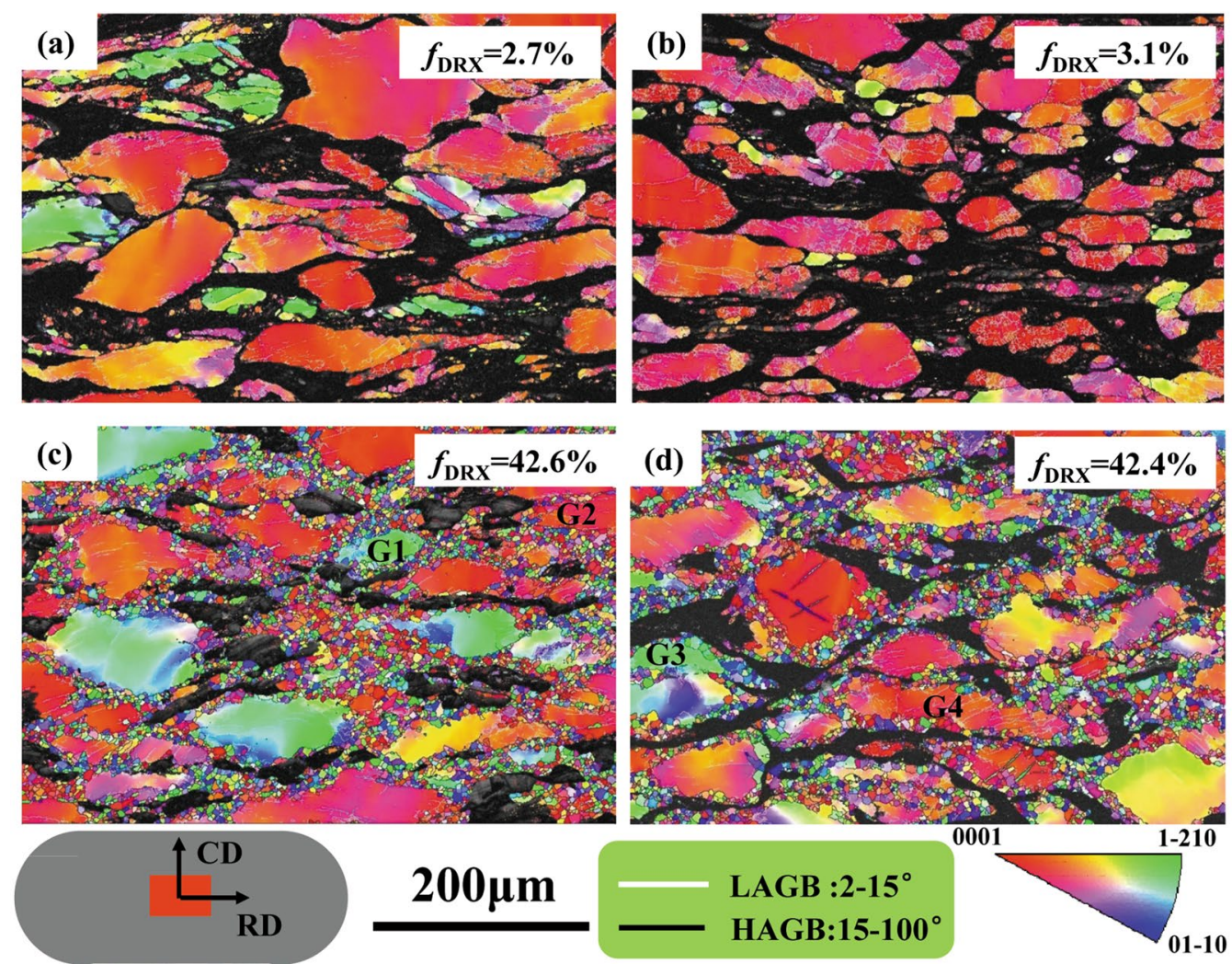

Fig. 7 Inverse pole figure of GWZK 114 alloy under normal-compression of a $350{ }^{\circ} \mathrm{C}, \mathbf{c} 450{ }^{\circ} \mathrm{C}$; can-compression of $\mathbf{b} 350{ }^{\circ} \mathrm{C}$, d $450{ }^{\circ} \mathrm{C}$

angle $\theta_{\text {local }}\left(>2^{\circ}-3^{\circ}\right.$ in Fig. 8 a, b). At $450{ }^{\circ} \mathrm{C}$ (Fig. 8d, e), a decreased density is observed and the corresponding local misorientation angles at most of the regions are reduced to a small range of $0^{\circ}-1^{\circ}$. Known from the enlarged images of select regions, although the LPSO phase is not successfully indexed, the kinked boundaries (indicated by black arrows) are roughly observed inside the matrix, which exactly implies the formation of the LPSO kinking [34]. As can be seen, larger $\theta_{\text {local }}$ values are focused at the kinked region, and compared with the normal-compression higher $\theta_{\text {local }}$ values are induced under the can-compression.

Figure $8 \mathrm{c}, \mathrm{f}$ shows the location misorientation distribution of the normal-compressed and can-compressed samples extracted from Fig. 8a, b, d, e. At $350^{\circ} \mathrm{C}$, the average local misorientation angles are $1.19^{\circ}$ for normal-compression and $1.41^{\circ}$ for cancompression. Under $450{ }^{\circ} \mathrm{C}$, the average local misorientation angles increased from $0.69^{\circ}$ for normal-compression to $0.79^{\circ}$ for can-compression. Theoretically, the geometry relationship between local misorientation angle $\theta_{\text {local }}$ and geometrically necessary dislocation (GND) density $\rho_{\mathrm{GND}}$ can be expressed as [33]:

$\rho_{\mathrm{GND}}=\frac{\theta_{\text {local }}}{b h}$, where the $b$ is the burger vector of basal $\langle a\rangle$ slip $(0.32 \mathrm{~nm})$. Here, basal $\langle a\rangle$ slip is chosen for its commonly highest activity owing to its lowest CRSS [35]. $h$ is the EBSD scanning step size of $0.8 \mu \mathrm{m}$. Through Eq. (1), the GND densities of final deformed specimens at different deformation conditions can be calculated and are listed in Table 1 . The GND densities of can-compression at $350{ }^{\circ} \mathrm{C}$ and $450{ }^{\circ} \mathrm{C}$ are relatively $18.5 \%$ and $14.5 \%$ higher than these for normalcompression. Although the calculated GND densities are parts of total dislocations, it still implies that a higher dislocation density should be induced during can-compression. A proportional relationship between GND density and total dislocation density can be prospected, as experimentally clarified by Jiang et al. [36]. The higher dislocation densities under larger hydrostatic pressures are also consistent with the observation reported by Zehetbauer et al. [27]. They declared that the increase in hydrostatic pressure allows a decrease in lattice diffusion, which in turn slows down the annihilation process of dislocations [33].

Figure 9 shows the texture of whole grains, deformed grains (denoted as UnDRX), and DRX grains extracted from Fig. 7. At $350{ }^{\circ} \mathrm{C}$ (Fig. 9a, b), typical basal textures are induced for all the grain types, meaning that most of the $c$-axis of grains was parallel to $\mathrm{CD}$. The whole texture intensities of 

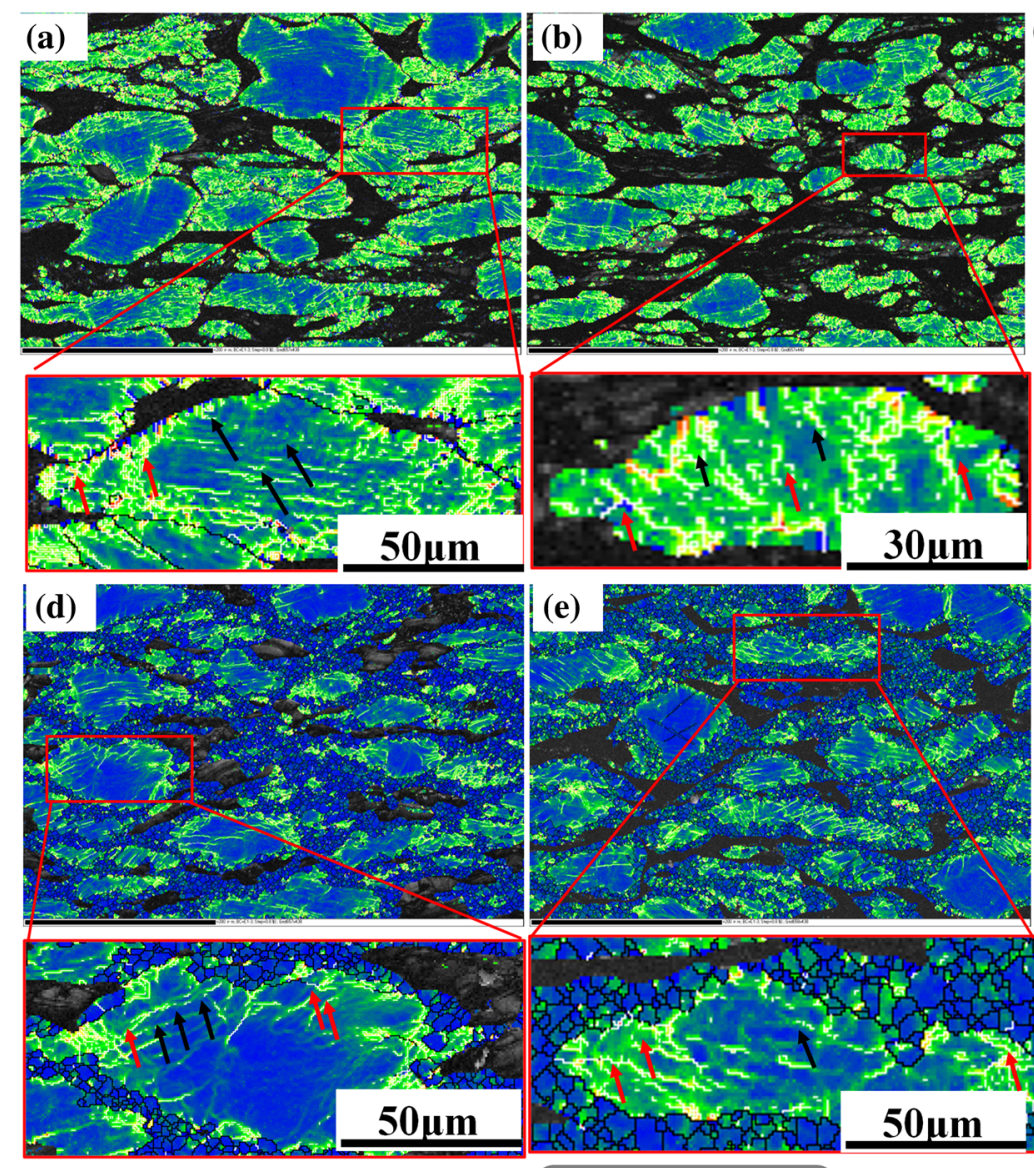

0
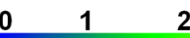

2

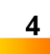

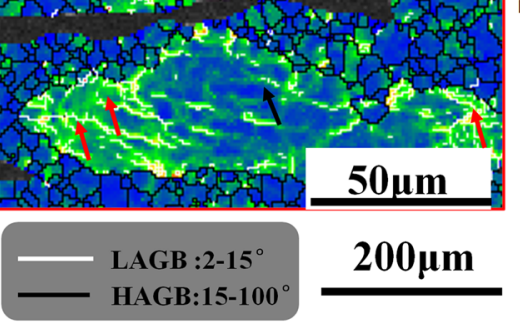
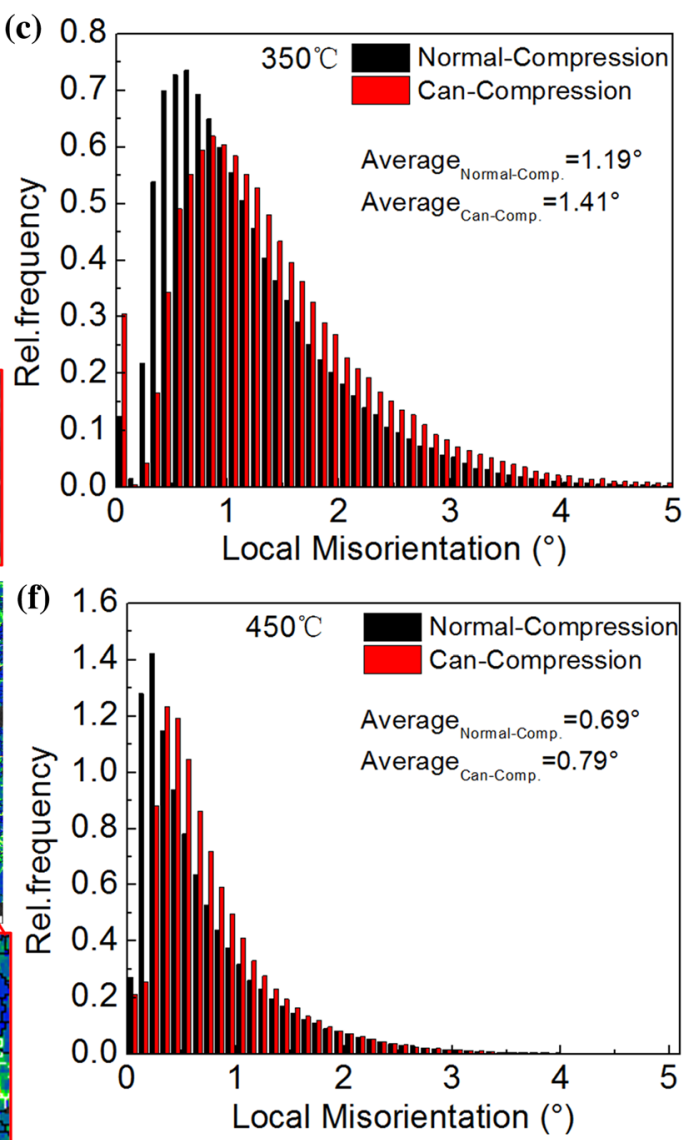

LPSO kink boundary

Low angle grain boundary

Fig. 8 Kernel average misorientation (KAM) maps of samples under normal-compression of $\mathbf{a} 350{ }^{\circ} \mathrm{C}, \mathbf{d} 450{ }^{\circ} \mathrm{C}$; can-compression of $\mathbf{b} 350{ }^{\circ} \mathrm{C}$, e $450{ }^{\circ} \mathrm{C}$; distribution of local misorientation of KAM under c $350{ }^{\circ} \mathrm{C}, \mathbf{f} 450{ }^{\circ} \mathrm{C}$

Table 1 Average local misorientation and calculated dislocation density under different conditions

\begin{tabular}{llllll}
\hline Contents & \multicolumn{2}{l}{ Normal-compression } & & \multicolumn{2}{l}{ Can-compression } \\
\cline { 2 - 3 } & $350{ }^{\circ} \mathrm{C}$ & $450{ }^{\circ} \mathrm{C}$ & & $350{ }^{\circ} \mathrm{C}$ & $450{ }^{\circ} \mathrm{C}$ \\
\hline$\theta_{\text {local }}\left({ }^{\circ}\right)$ & 1.19 & 0.69 & & 1.41 & 0.79 \\
$\rho_{\mathrm{GND}}\left(/ \mathrm{m}^{2}, \times 10^{14}\right)$ & 0.96 & 0.33 & & 1.36 & 0.43 \\
\hline
\end{tabular}

normal-compression and can-compression are similar to be 13.02 m.u.d. and 12.15 m.u.d., respectively. For the can-compression, the main component of basal texture is much closer to $\mathrm{CD}$, and similarly, typical basal textures are obtained for the UnDRX and DRX grains. With the increase in temperature from 350 to $450{ }^{\circ} \mathrm{C}$, the whole basal texture intensities significantly decreased to 8.75 m.u.d. for normal-compression (Fig. 9c) and 6.75 m.u.d. for can-compression (Fig. 9d). The main reason for this weaker texture is probably the more randomly orientated DRX grains with low intensities of 2.09 m.u.d. for normalcompression and 1.93. m.u.d. for can-compression. In other words, at high temperature, the can-compression (e.g., high hydrostatic pressure) still poses negligible influence on the texture evolution.

\subsection{DRX Mechanism Under Two Hydrostatic Pressure Compressions}

From the microstructure characteristics shown in Fig. 4g, h, $7 \mathrm{c}, \mathrm{d}$, significant DRX behavior of GWZK 114 alloy occurs at $450{ }^{\circ} \mathrm{C}$ under both normal-compression and can-compression conditions. Therefore, the DRX mechanism under two compression conditions is further analyzed in Figs. 10, 11, 12 and 13, where the magnified EBSD results of the selected four typical grains (G1, G2, G3, G4) with different orientations from Fig. 7c and d are presented. Additionally, accumulative misorientations along the selected lines A-B in Fig. 10a and E-F in Fig. 11a indicate the gradual lattice rotation from the grain interior to the grain boundary, with misorientation angle of $12^{\circ}$ and $25^{\circ}$, respectively, as 


\section{Whole}

(a)

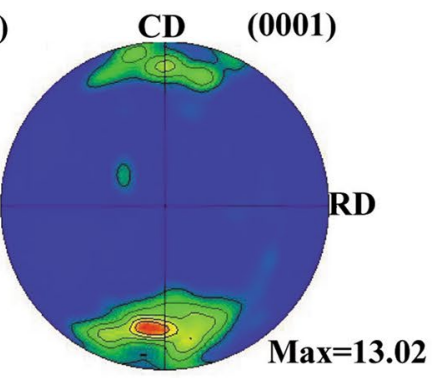

(b)

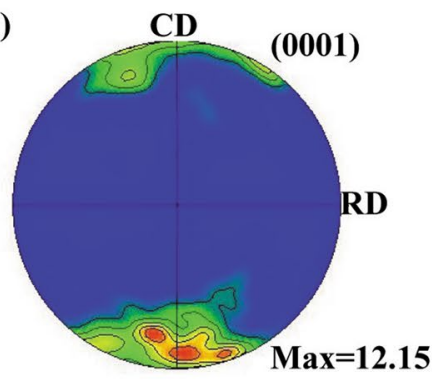

(c)

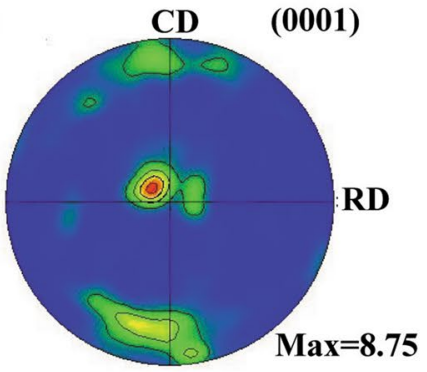

(d)

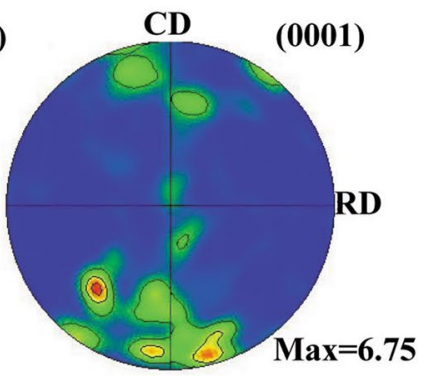

UnDRX
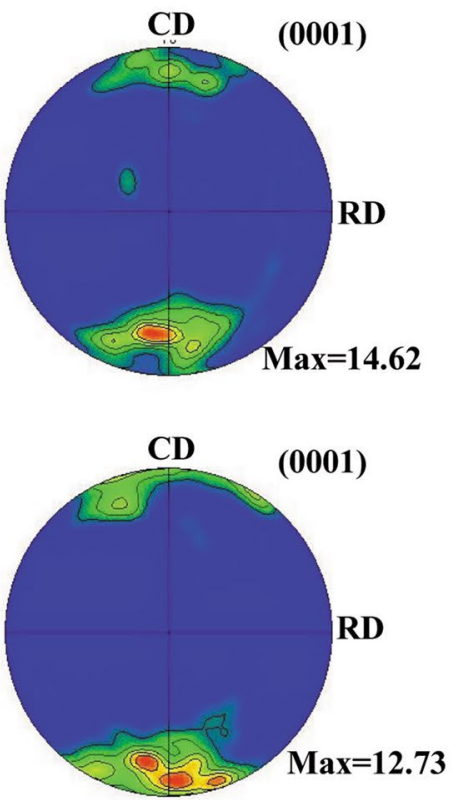

CD

(0001)
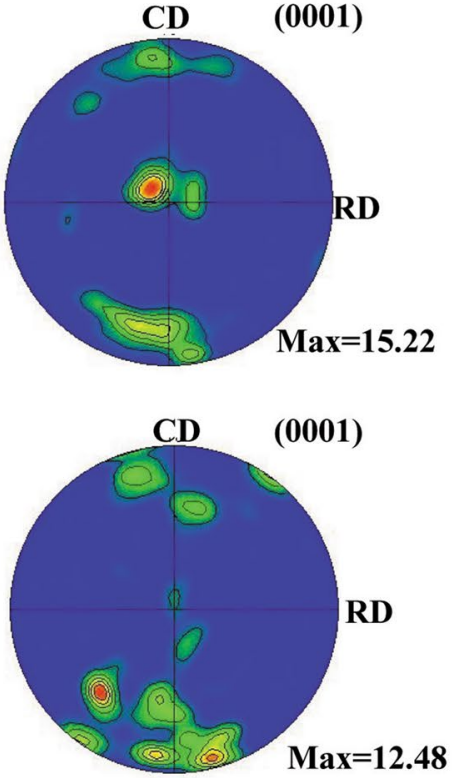

DRX
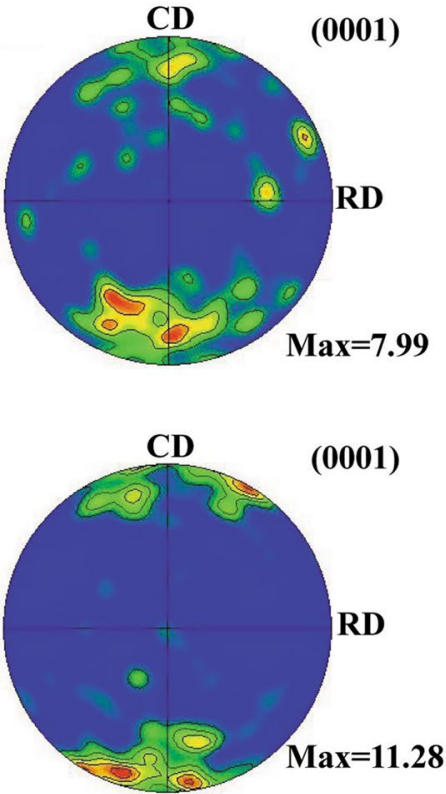

CD

(0001)
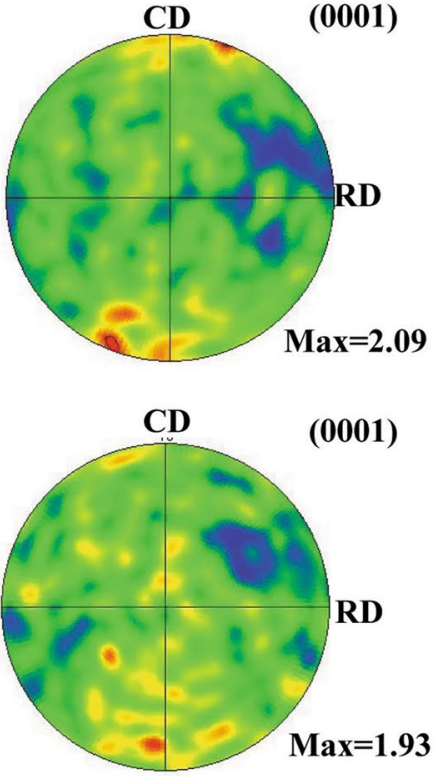

Fig. 9 (0001) pole figures of GWZK 114 alloy under normal-compression of a $350{ }^{\circ} \mathrm{C}, \mathbf{c} 450{ }^{\circ} \mathrm{C}$; can-compression of $\mathbf{b} 350{ }^{\circ} \mathrm{C}$, d $450{ }^{\circ} \mathrm{C}$

shown in Fig. 10b and 11b. Meanwhile, there are amount of LAGBs (white lines) at the vicinity of GBs as red arrows indicated in Figs. 10a and 11a. In further deformation, the LAGBs formed sub-grains and then transform into DRX grains by trapping more mobile dislocations and increasing the boundary misorientation. Based on the above results, it manifests that the continuous DRX (CDRX) is the dominant deformation mechanism under both the normal-compression and can-compression conditions [37,38]. It is well known that the evolution of misorientation highly depends on the activity of dislocations. Thus, the Schmid factors of slip systems of G1 and G3 were calculated by Channel 5 software as shown in Figs. 10c and 11c. The average SFs for basal $\langle a\rangle$ slip were only 0.118 and 0.099 , respectively, whereas the average SFs for the prismatic $\langle a\rangle$ and pyramidal $\langle\boldsymbol{c}+\boldsymbol{a}\rangle$ slips were higher than 0.45 , indicating the highly mobility of non-basal slip dislocations. The cross-slip of $\langle a\rangle$ dislocations on non-basal planes is needed for CDRX process 


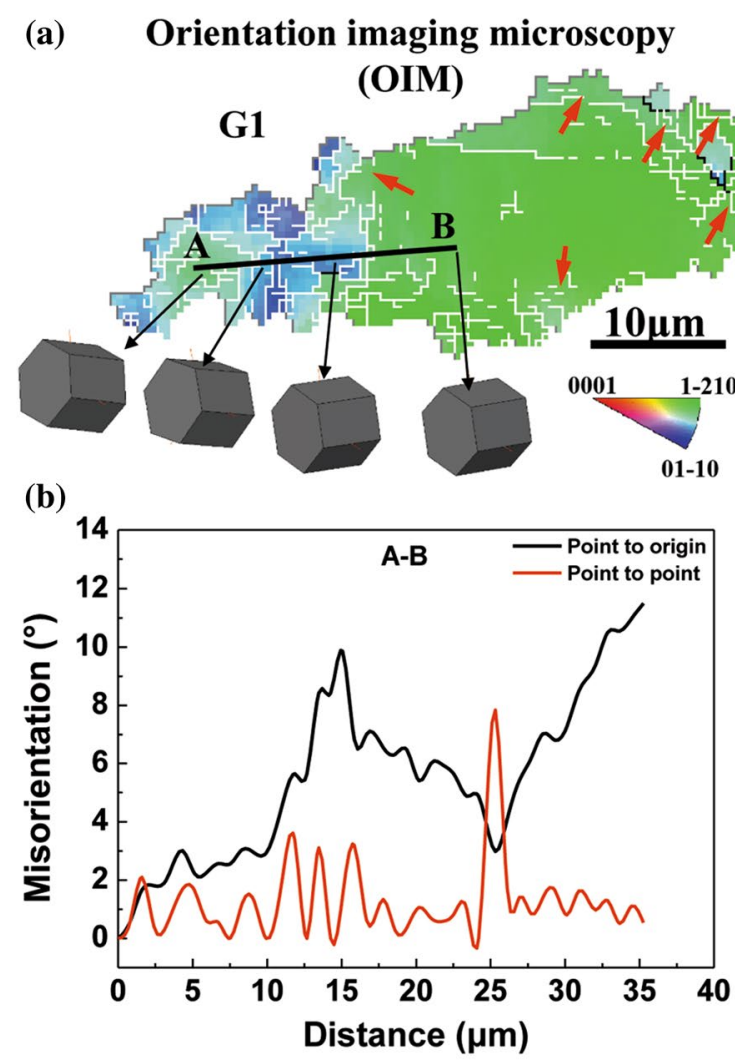

(c) Schimid Factor (SF)
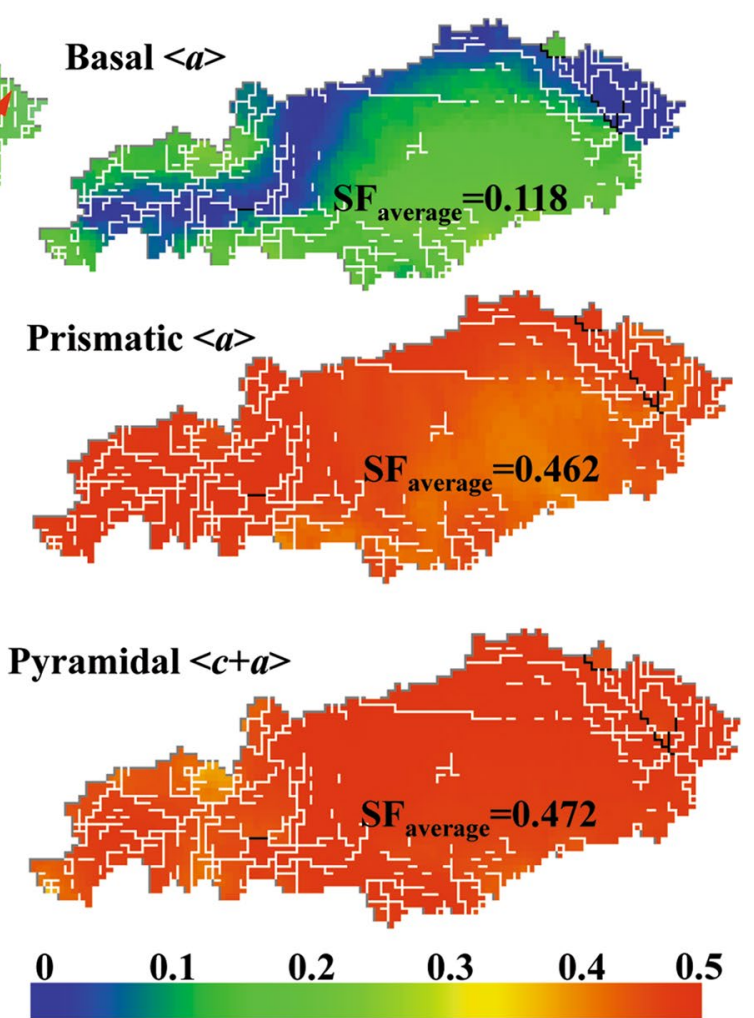

Fig. 10 DRX behavior of grain G1 in Fig. 7c: a orientation imaging microscopy (OIM); b line profile of misorientation angle along the lines A-B in a; c Schmid factors of basal $\langle\boldsymbol{a}\rangle$, prismatic $\langle\boldsymbol{a}\rangle$ and pyramidal $\langle\boldsymbol{c}+\boldsymbol{a}\rangle$ slip systems for grain G1 under normal-compression condition. (Basal $\langle a\rangle:\{0001\}\langle 11 \overline{2} 0\rangle$; prismatic $\langle a\rangle:\{10 \overline{1} 0\}\langle 11 \overline{2} 0\rangle$; pyramidal $\langle\boldsymbol{c}+\boldsymbol{a}\rangle:\{11 \overline{2} 2\}\langle 11 \overline{2} 3\rangle$ )

to form the recrystallization nuclei [39]. During cross-slip, $\langle a\rangle$ screw dislocation can be transformed to an edge $\langle a\rangle$ dislocation through the Friedel-Escaig mechanism [40]. After that, the edge dislocation can readily climb for its high value of stacking fault energy [41]. Thus, through cross-slip and climbing, these dislocations rearranged in the vicinity of boundaries, resulting in profuse of LAGBs (Figs. 10a, 11a). With the increase in strain, more activated non-basal $\langle a\rangle$ dislocations accumulated at the grain boundaries. The continuous absorption of these non-basal $\langle\boldsymbol{a}\rangle$ dislocations in the LAGBs leads to form HAGBs and the DRXed grains (Figs. 10a, 11a) [42].

On the other hand, the DRX behavior of LPSO phase contained $\mathrm{Mg}$ alloy has been widely reported to be related to LPSO kinking [2, 28, 43]. Figures 12a and 13a show there are some necklace-like DRX grains at the vicinity of block 18R-LPSO phase (black areas in Figs. 12a, 13a) and chain-like DRX grains cross the matrix. As Fig. 2 presents, two kinds of LPSO phases (intergranular block 18R-LPSO phase and intragranular lamellar 14H-LPSO phase) exist in as-solution GWZK 114 alloy, which influenced the DRX behavior by different mechanisms. As indicated in Figs. 12b and $13 \mathrm{~b}$, the intergranular block 18R-LPSO phases can hinder the movement of dislocations at the interface between LPSO phase and $\alpha-\mathrm{Mg}$ matrix, and then promote the formation of sub-grains and related DRX grains via particlestimulated nucleation (PSN) mechanism (as called PSN type 1) [43]. As for the lamellar 14H-LPSO phases inside the matrix, similar enhancement effect was also declared as that $\langle\boldsymbol{c}+\boldsymbol{a}\rangle$ dislocations with higher SF value of 0.426 (normalcompression) and 0.406 (can-compression) can accumulate around the LPSO phases resulting in chain-like DRX grains inside the matrix (PSN type 2 in Figs. 12b, 13b) [2].

\section{Discussion}

Given as the aforementioned experimental observations, it is ascertained that the imposed level of hydrostatic pressure plays an important role on the kinking behavior of LPSO phase. Under higher hydrostatic pressure, LPSO phases, including both the lamellar 14H and block 18R types, undergo enhanced kinking behaviors. However, the DRX 
(a) Orientation imaging microscopy (OIM)

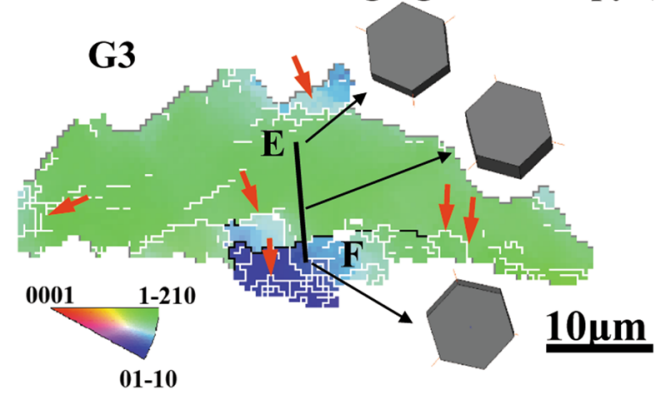

(b)

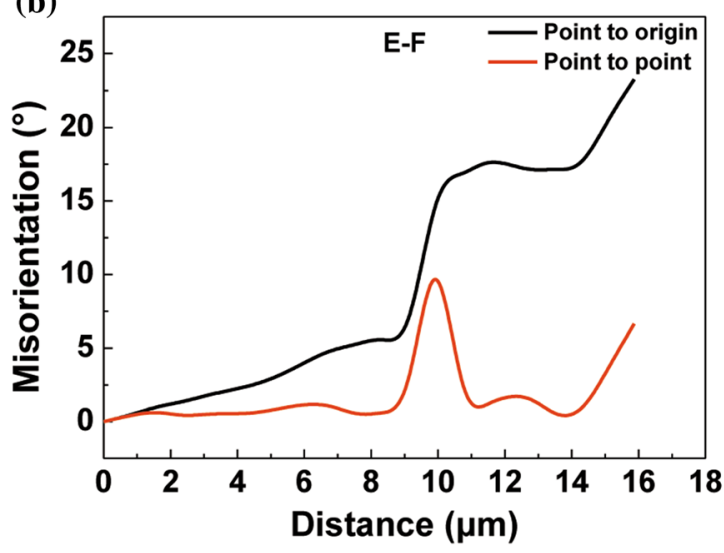

(c) Schimid Factor (SF)

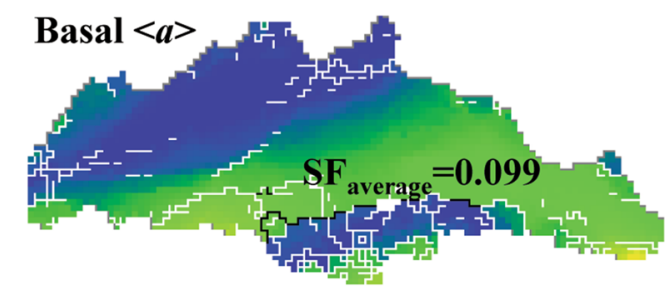

Prismatic $<a>$

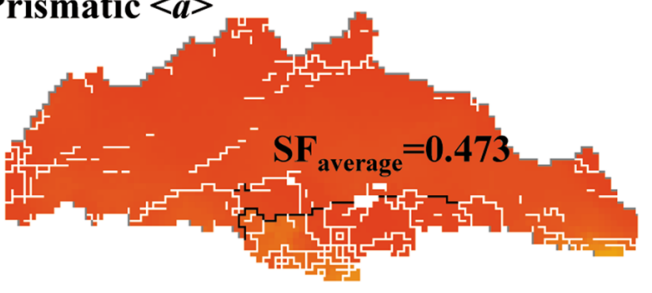

Pyramidal $<c+a>$

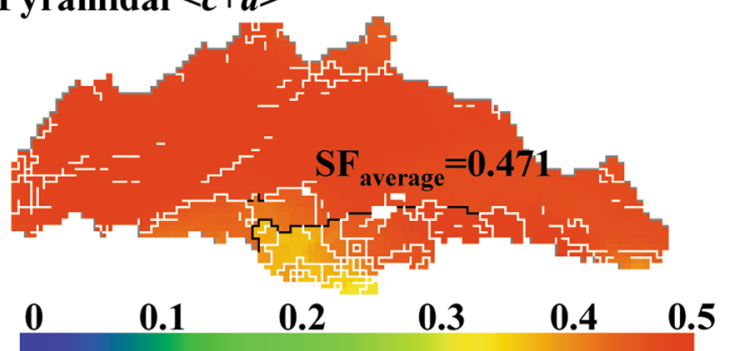

Fig. 11 DRX behavior of grain G3 in Fig. 7d: a orientation imaging microscopy (OIM); b line profile of misorientation angle along the lines $\mathrm{E}-\mathrm{F}$ in $\mathbf{a} ; \mathbf{c}$ the Schmid factors of basal $\langle\boldsymbol{a}\rangle$, prismatic $\langle\boldsymbol{a}\rangle$ and pyramidal $\langle\boldsymbol{c}+\boldsymbol{a}\rangle$ slip systems for grain $\mathrm{G} 3$ under can-compression condition

fraction, grain size, and crystallographic texture evolution exhibit slight correlation with the hydrostatic pressure.

\subsection{Effect of Hydrostatic Pressure on LPSO Kink Behavior}

Combining the experimental observations (Figs. 4, 5, 6, 7, 8) with different dislocation densities (Table 1), distinctive kinking behaviors between 14H-LPSO phase and 18R-LPSO phase under normal-compression and can-compression are schematized in Fig. 14. As clearly reported, the kinking of LPSO phases, including both the $14 \mathrm{H}$ and $18 \mathrm{R}$ types, is controlled by the progressive lattice rotation by generation and synchronized slip of dislocation pairs of opposite signs on the basal planes during compression [14]. From Fig. 14a, once the inclined angle of $\alpha$ between CD and 14H-LPSO phase is small, kinking of $14 \mathrm{H}$-LPSO phase with low strength (e.g., micro-hardness of $70.7 \mathrm{HV}$ [28]) is facilitated for the highly active basal $\langle\boldsymbol{a}\rangle$ slip [7]. In contrast, the 18R-LPSO phase with higher strength (e.g., micro-hardness of 104.6 HV [28]) will kink instead under the case of high $\alpha$ angle, as shown in Fig. 14b. Similarly, suppressed kinking behavior of $14 \mathrm{H}-\mathrm{LPSO}$ phase was also experimentally observed under tension parallel to basal planes [16], which exactly shows the same stress sense with the compression nearly perpendicular to 14H-LPSO phase's basal planes (e.g., high angle of $\alpha$ in Fig. 14b).

Since the formation of kink band is closely related to the movement of basal $\langle a\rangle$ dislocation, the larger dislocation density under high hydrostatic pressure (e.g., can-compression) is prone to stimulate more operation of oppositely signed dislocation pairs. Consequently, it can enhance the formation of kink band for 14H and 18R-LPSO phases, as illustrated in Fig. 14. More specifically, the increased kinking times and decreased kink width are obtained for the LPSO phase under can-compression, as shown in Fig. 6.

\subsection{Origin of the Similar DRX Fractions Under Normal-Compression and Can-Compression}

As mentioned in Sect. 3.5 and 3.6, the hydrostatic pressure exerts little influence on the DRX mechanism as well as the resultant DRX fraction (Fig. 7c, d). It is worth noting that as a deformable phase, the kinking of LPSO phase can accommodate the plastic deformation and thus release the local stress/strain [7]. Since the DRX behaviors are mainly 

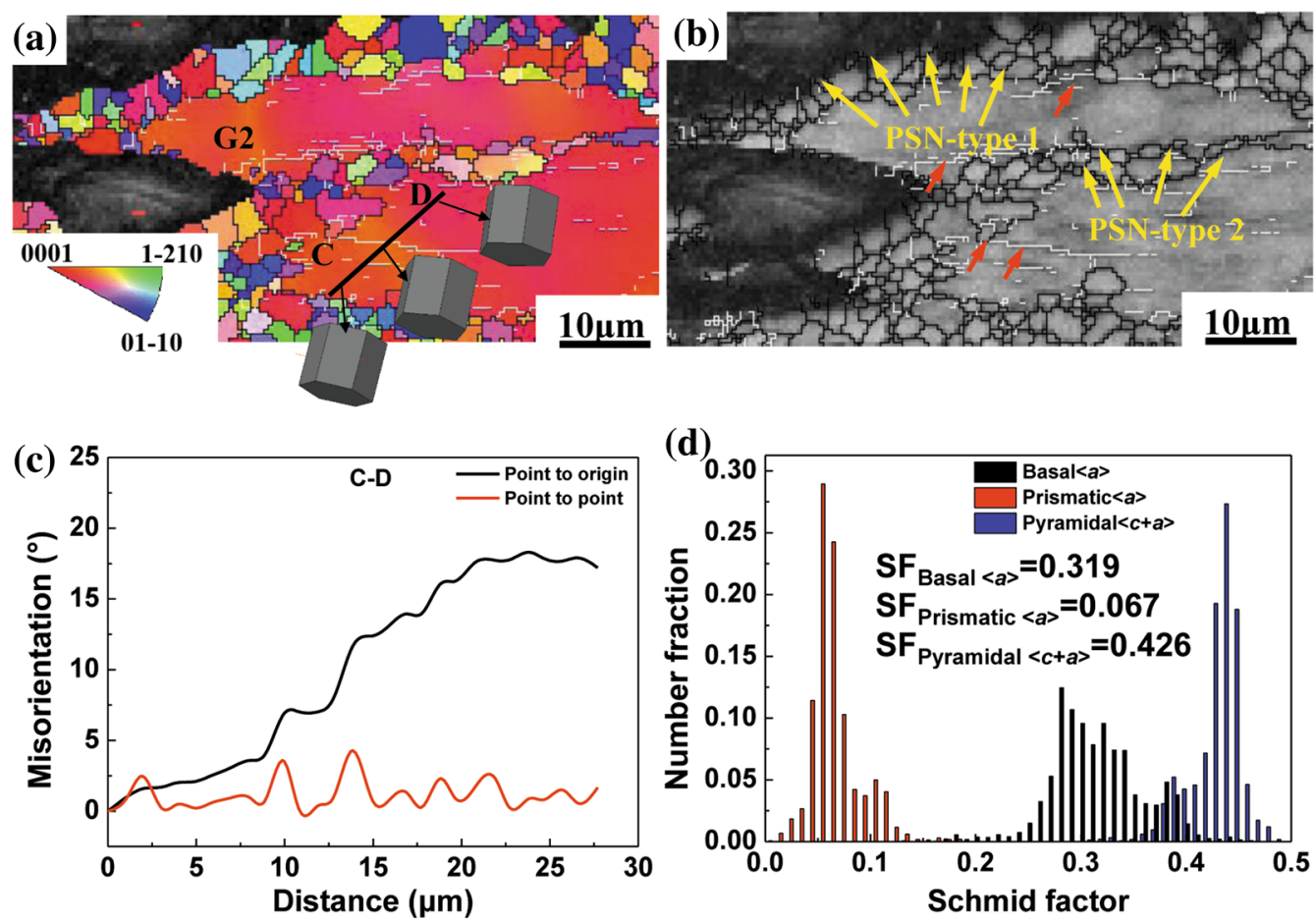

Fig. 12 DRX behavior of grain G2 in Fig. 7c: a orientation imaging microscopy (OIM); b band contract figure; $\mathbf{c}$ line profile of misorientation angle along the lines C-D in $\mathbf{a}$; $\mathbf{d}$ the Schmid factors of basal $\langle\boldsymbol{a}\rangle$, prismatic $\langle\boldsymbol{a}\rangle$ and pyramidal $\langle\boldsymbol{c}+\boldsymbol{a}\rangle$ slip systems for grain G2 under normalcompression condition
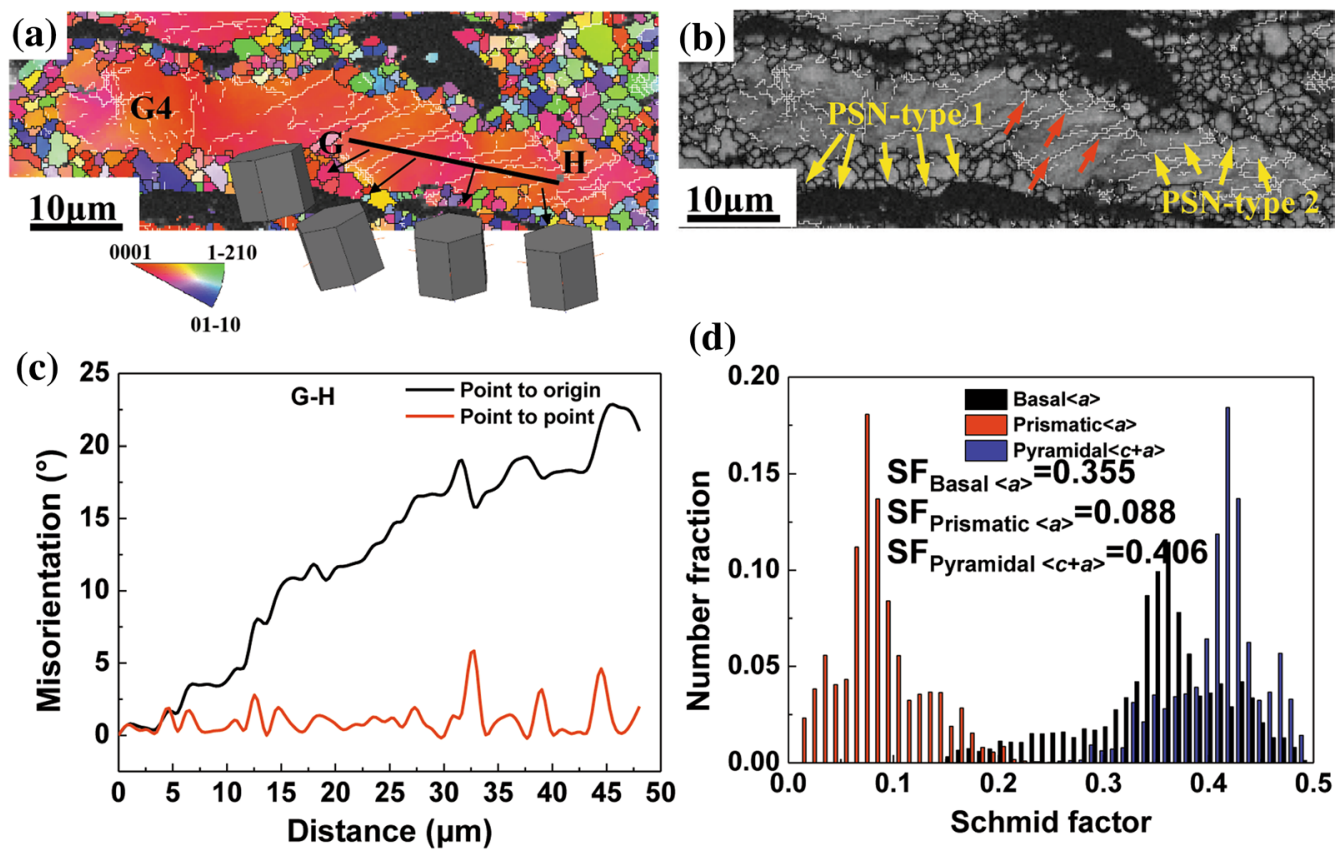

(d)

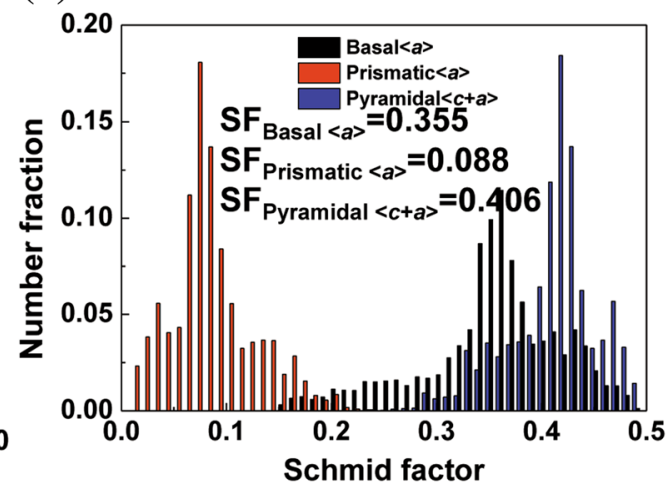

Fig. 13 DRX behavior of grain G4 in Fig. 7d: a orientation imaging microscopy (OIM); $\mathbf{b}$ band contract figure $\mathbf{c}$ line profile of misorientation angle along the lines G-H in $\mathbf{a}, \mathbf{d}$ Schmid factors of basal $\langle\boldsymbol{a}\rangle$, prismatic $\langle\boldsymbol{a}\rangle$ and pyramidal $\langle\boldsymbol{c}+\boldsymbol{a}\rangle$ slip systems for grain G4 under can-compression condition 

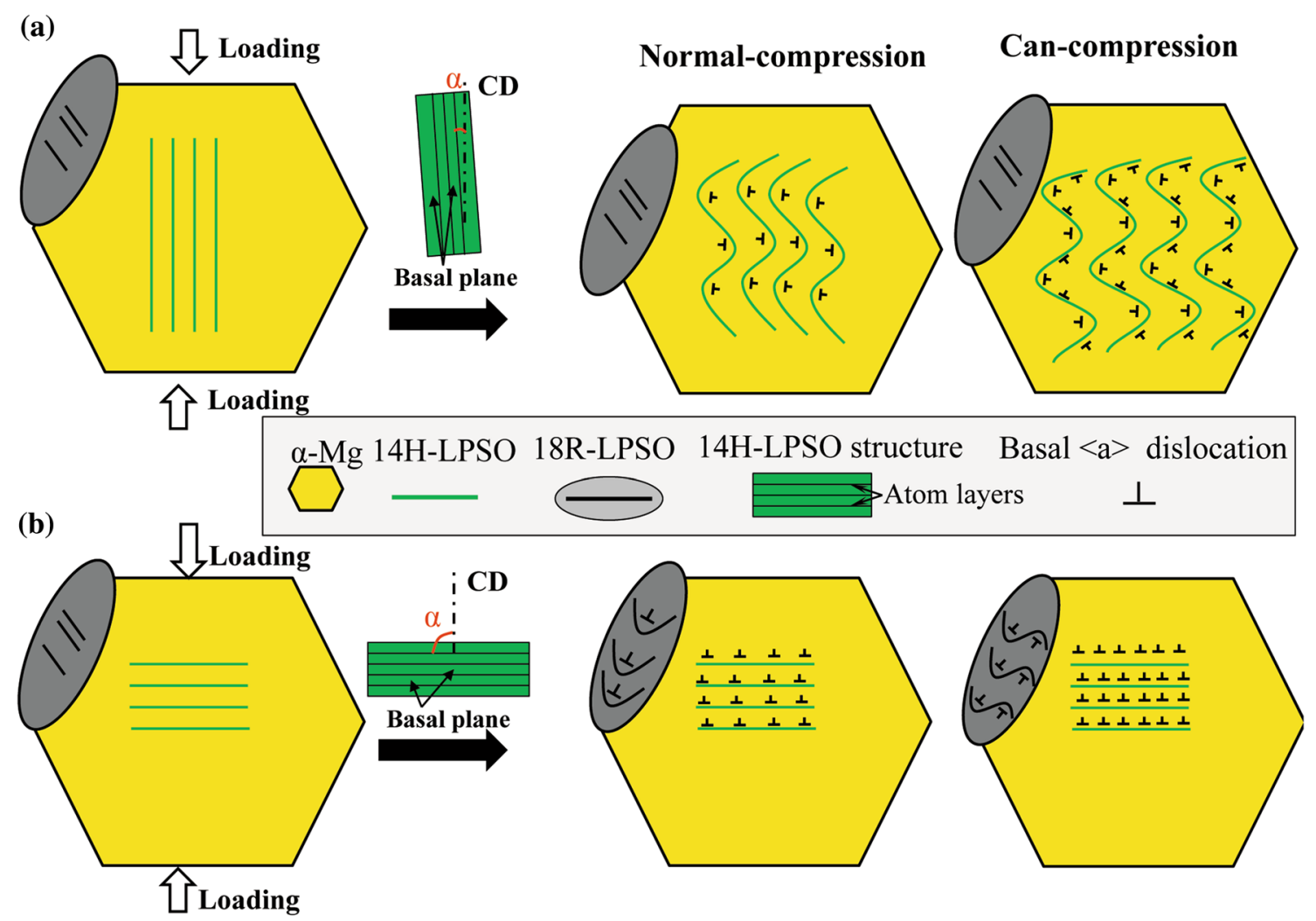

Fig. 14 Schematic of kink band formation under different loading conditions: a compression with a small inclined $\alpha$ angle of CD from 14H-LPSO phase's basal planes; $\mathbf{b}$ compression with a high inclined $\alpha$ angle of CD from 14H-LPSO phase's basal planes

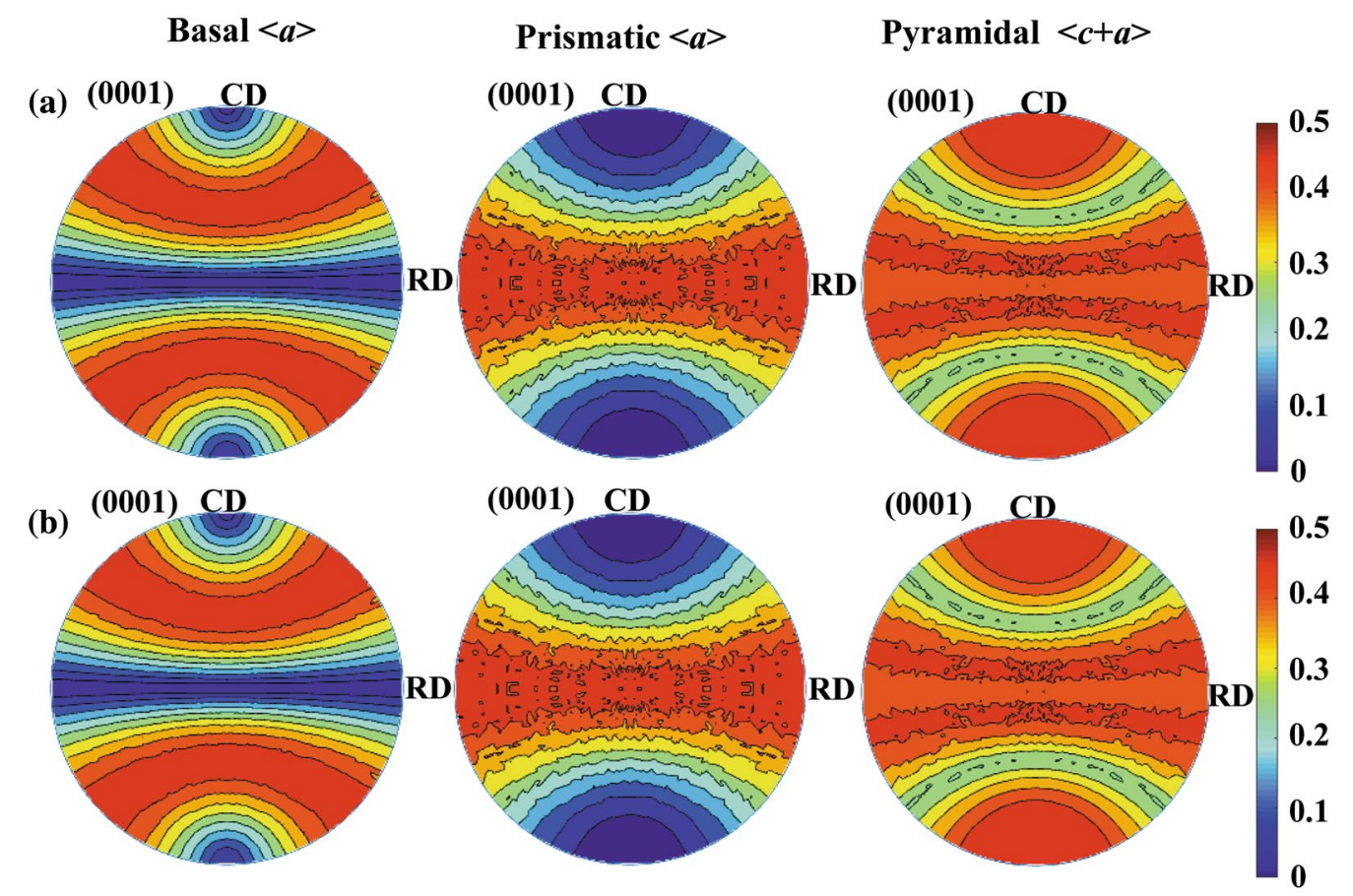

Fig. 15 Effective Schmid factor distribution of GWZK 114 alloy on (0001) PFs under 
controlled by the dislocation movement derived by the imposed strain, the kinked LPSO phases, especially the 18R-LPSO phase, can reduce the amount of plastic deformation which the matrix suffers [2]. In other words, the LPSO kinking partially diminishes the stored energy inside the $\alpha-\mathrm{Mg}$ matrix, which in turn delays the CDRX behavior. Such retarded effect on DRX behavior caused by LPSO kinking has also been experimentally proved and phenomenally modeled in our previous work [28]. That is, under can-compression, severe LPSO kinking occurs attributed to a higher dislocation density, which accordingly stimulates a more apparent DRX behavior via the PSN mechanism, as observed in Fig. 13a, and simultaneously accommodates a higher amount of strain. Thus, at close levels of strain (Fig. 1c), the nearly same DRX fractions are measured for normal-compression and can-compression, as a likely result of simultaneous operations of the favorable role (e.g., PSN effect) and unfavorable role (strain accommodation) of LPSO kinking on the DRX kinetics.

\subsection{Effect of Hydrostatic Pressure on Texture Evolution}

As given in Fig. 9, basal type textures with similar texture intensity are induced for deformed matrix for both the low and high hydrostatic pressure, e.g., normal-compressions and can-compressions. Moreover, taking advantage of the effective Schmid factor (ESF) concept proposed in our recent work, the activation of slip modes under complex stress state in normal-compressions and can-compressions can be well predicted, where the stress states are exacted from the FEM simulation shown in Fig. 1a, b [44]. Figure 15 displays that (0001) PF distribution of ESF values of basal $\langle a\rangle$, prismatic $\langle\boldsymbol{a}\rangle$, and pyramidal $\langle\boldsymbol{c}+\boldsymbol{a}\rangle$ slips under two compression conditions. Obviously, the almost same distributions are plotted for all three slips, which means that the activated slip systems are nearly identical under the two conditions. From Fig. 15, both basal $\langle a\rangle$ and prismatic $\langle a\rangle$ slips show low ESF regions at the CD. At elevated temperature, the deformed textures of $\mathrm{Mg}$ alloy are mainly determined by the slipping related plastic spin rotation, and usually, the activated slips tend to reorientate the deformed grains to low ESF regions for the purposes of stress migration [45-47].

\section{Conclusions}

In this study, the as-homogenized casting GWZK114 alloys were normal-compressed (low hydrostatic pressure) and cancompressed (high hydrostatic pressure) under $300-450{ }^{\circ} \mathrm{C}$. The effects of hydrostatic pressure on microstructure evolution and LPSO kink behavior were systematically investigated. The main conclusions obtained from this study can be summarized as follows:

1. At $300{ }^{\circ} \mathrm{C}$ and $350{ }^{\circ} \mathrm{C}$, the deformation microstructure consists of elongated grains and multiple LPSO kink bands. At $400{ }^{\circ} \mathrm{C}$, the finer DRX grains occur at the grain boundary and the LPSO phase gently kinks. When deformed at $450{ }^{\circ} \mathrm{C}$, the bimodal microstructure is observed with extensive formation of DRX grains.

2. Compared with normal-compression, both the $14 \mathrm{H}$-LPSO phase and 18R-LPSO phase during cancompression undergo much severe kinking with a larger times and a smaller relative width $(d / L)$, which may be caused by a larger dislocation density under higher hydrostatic pressure. Furthermore, a competitive kinking behavior between intergranular 18R-LPSO phase and intragranular 14H-LPSO phase is also observed.

3. For normal-compression and can-compression, the same continuous dynamic recrystallization mechanism (CDRX) is operated. The hydrostatic pressure presents slight influence on the DRX fraction, and similar deformed textures are resulted from similarity in the activation of plastic deformation modes under the two levels of hydrostatic pressure with the randomly orientated DRX grains efficiently weakening the texture.

Acknowledgements This work was financially supported by the National Natural Science Foundation of China (Contract No. 51305188).

\section{References}

[1] Z. Zeng, N. Stanford, C.H.J. Davies, J.F. Nie, N. Birbilis, Int. Mater. Rev. 64, 27 (2019)

[2] C. Xu, T. Nakata, X. Qiao, M.Y. Zheng, K. Wu, S. Kamado, Sci. Rep. 7, 40846 (2017)

[3] S.J. Meng, H. Yu, S.D. Fan, Q.Z. Li, S.H. Park, J.S. Suh, Y.M. Kim, X.L. Nan, M.Z. Bian, F.X. Yin, W.M. Zhao, B.S. You, K.S. Shin, Acta Metall. Sin. (Engl. Lett.) 32, 145 (2019)

[4] B.L. Mordike, T. Ebert, Mater. Sci. Eng. A 302, 37 (2001)

[5] L.Z. Liu, F.S. Pan, X.H. Chen, Y.D. Huang, B. Song, H. Yang, N. Hort, Vacuum 155, 445 (2018)

[6] B.N. Du, Z.Y. Hu, L.Y. Sheng, D.K. Xu, Y.F. Zheng, T.F. Xi, Acta Metall. Sin. (Engl. Lett.) 31, 351 (2018)

[7] J. Yang, J. Peng, M. Li, E.A. Nyberg, F.S. Pan, Acta Metall. Sin. (Engl. Lett.) 30, 53 (2017)

[8] B. Pourbahari, H. Mirzadeh, M. Emamy, Mater. Sci. Eng. A 680, 39 (2017)

[9] Q.Z. Liu, X.F. Ding, Y.P. Liu, X.J. Wei, J. Alloys Compd. 690, 961 (2017)

[10] F.Q. Bu, Q. Yang, K. Guan, X. Qiu, D.P. Zhang, W. Sun, T. Zheng, X.P. Cui, S.C. Sun, Z.M. Tang, X.J. Liu, J. Meng, J. Alloys Compd. 688, 1241 (2016)

[11] M.X. Wang, H. Zhou, L. Wang, J. Rare Earth 25, 233 (2007)

[12] F. Zhong, H.J. Wu, Y.L. Jiao, R.Z. Wu, J.H. Zhang, L.G. Hou, M.L. Zhang, J. Mater. Sci. Technol. 39, 124 (2020) 
[13] X.H. Shao, Z.Q. Yang, X.L. Ma, Acta Mater. 58, 4760 (2010)

[14] H. Gao, K. Ikeda, T. Morikawa, K. Higashida, H. Nakashima, Mater. Lett. 146, 30 (2015)

[15] K. Máthis, G. Farkas, G. Garcés, J. Gubicza, Mater. Lett. 190, 86 (2017)

[16] R. Chen, S. Sandlöbes, X.Q. Zeng, D.J. Li, K.K. Sandra, D. Raabe, Mater. Sci. Eng. A 682, 354 (2017)

[17] T. Homma, N. Kunito, S. Kamado, Scr. Mater. 61, 644 (2009)

[18] C. Xu, M.Y. Zheng, S. Xu, K. Wu, E.D. Wang, G.H. Fan, S. Kamado, Mater. Sci. Eng. A 643, 137 (2015)

[19] L. Li, Y. Wang, C.C. Zhang, T. Wang, H. Lv, W.B. Yu, Vacuum 173, 109157 (2020)

[20] C. Xu, S.W. Xu, M.Y. Zheng, K. Wu, E.D. Wang, S. Kamado, G.J. Wang, X.Y. Lv, J. Alloys Compd. 524, 46 (2012)

[21] G.S. Zhang, Z.M. Zhang, Y. Du, Z.M. Yan, X. Che, Materials 11, 2092 (2018)

[22] B. Li, B.G. Teng, D.G. Luo, Acta Metall. Sin. (Engl. Lett.) 31, 1009 (2018)

[23] F.P. Bullen, F. Henderson, M.M. Hutchison, H.L. Wain, Philos. Mag. 9, 285 (1964)

[24] F.P. Bullen, F. Henderson, H.L. Wain, M.S. Paterson, Philos. Mag. 101, 803 (1964)

[25] J.J. Lewandowski, P. Lowhaphandu, Int. Mater. Rev. 43, 145 (1998)

[26] I.E. French, P.F. Weinrich, Metall. Trans. A 6, 785 (1975)

[27] M.J. Zehetbauer, H.P. Stüwe, A. Vorhauer, E. Schafler, J. Kohout, Adv. Eng. Mater. 5, 330 (2003)

[28] H.X. Zhang, S.F. Chen, M. Cheng, C. Zheng, S.H. Zhang, Acta. Metall. Sin. (Engl. Lett.) 32, 1122 (2019)

[29] D. Pradhan, G.S. Mahobia, K. Chattopadhyay, D.C. Fernando, N. Paulose, S.N.N. Babu, V. Singh, Mater. Res. Express 6, 0965a6 (2019)
[30] Y. Lou, J.W. Yoon, H. Huh, Int. J. Plast. 54, 56 (2014)

[31] J.B. Shao, Z.Y. Chen, C. Tao, C.M. Liu, Metall. Mater. Trans. A 51, $1911(2020)$

[32] X.J. Zhou, C.M. Liu, Y.H. Gao, S.N. Jiang, X.Z. Han, Z.Y. Cheng, Metall. Mater. Trans. A 48, 3060 (2017)

[33] A.P. Zhilyaev, S.N. Sergeev, T.G. Langdon, J. Mater. Res. Technol. 3, 338 (2014)

[34] K. Hagihara, M. Yamasaki, M. Honnami, H. Izuno, M. Tane, T. Nakano, Y. Kawamura, Philos. Mag. 95, 132 (2015)

[35] M.R. Barnett, Metall. Mater. Trans. A 34, 1799 (2003)

[36] J. Jiang, T.B. Britton, A.J. Wilkinson, Acta Mater. 94, 193 (2015)

[37] S.S.A. Shah, M.G. Jiang, D. Wu, U. Wasi, R.S. Chen, Acta Metall. Sin. (Engl. Lett.) 31, 923 (2018)

[38] S. Biswas, B. Beausir, L.S. Toth, S. Suwas, Acta Mater. 61, 5263 (2013)

[39] A. Galiyev, R. Kaibyshev, G. Gottstein, Acta Mater. 49, 1199 (2001)

[40] A. Couret, D. Caillard, Acta Metall. 33, 1447 (1985)

[41] W. Püschl, G. Schoeck, H.O.K. Kirchner, Philos. Mag. 56, 553 (1987)

[42] M.G. Jiang, C. Xu, G.H. Fan, T. Nakata, C.S. Lao, R.S. Chen, S. Kamado, E.H. Han, B.H. Lu, Acta Mater. 157, 53 (2018)

[43] T. Sakai, A. Belyakov, R. Kaibyshev, H. Miura, J.J. Jonas, Prog. Mater. Sci. 60, 130 (2014)

[44] S.F. Chen, H.W. Song, S.H. Zhang, M. Cheng, C. Zheng, M.G. Lee, Scr. Mater. 167, 51 (2019)

[45] S.F. Chen, H.W. Song, S.H. Zhang, M. Cheng, M.G. Lee, J. Alloys Compd. 805, 138 (2019)

[46] C.D. Barrett, A. Imandoust, A.L. Oppedal, K. Inal, M.A. Tschopp, H.E. Kadiri, Acta Mater. 128, 270 (2017)

[47] Y.N. Wang, J.C. Huang, Mater. Chem. Phys. 81, 11 (2003) 